\title{
U.K. HiGEM: impacts of desert dust radiative forcing in a high-resolution atmospheric GCM
}

Article

Published Version

Woodage, M. and Woodward, S. (2014) U.K. HiGEM: impacts of desert dust radiative forcing in a high-resolution atmospheric GCM. Journal Of Climate, 27 (15). pp. 59075928. ISSN 1520-0442 doi: https://doi.org/10.1175/JCLI-D-1300556.1 Available at https://centaur.reading.ac.uk/67169/

It is advisable to refer to the publisher's version if you intend to cite from the work. See Guidance on citing.

Published version at: http://journals.ametsoc.org/doi/abs/10.1175/JCLI-D-13-00556.1

To link to this article DOI: http://dx.doi.org/10.1175/JCLI-D-13-00556.1

Publisher: American Meteorological Society

All outputs in CentAUR are protected by Intellectual Property Rights law, including copyright law. Copyright and IPR is retained by the creators or other copyright holders. Terms and conditions for use of this material are defined in the End User Agreement.

www.reading.ac.uk/centaur 
Central Archive at the University of Reading

Reading's research outputs online 


\title{
U.K. HiGEM: Impacts of Desert Dust Radiative Forcing in a High-Resolution Atmospheric GCM
}

\author{
M. J. WOODAGE \\ National Centre for Earth Observation, Department of Meteorology, University of Reading, Reading, \\ United Kingdom \\ S. WOODWARD \\ Met Office Hadley Centre, Exeter, United Kingdom
}

(Manuscript received 13 September 2013, in final form 26 February 2014)

\begin{abstract}
This work investigates the impacts of mineral dust aerosol on climate using the atmospheric component of the U.K. High-Resolution Global Environmental Model (HiGEM) with an interactive embedded mineral dust scheme. It extends earlier work by Woodage et al. in which direct radiative forcing due to dust was calculated and in which it was reported that the global total dust burden was increased when this was included in the model. Here this result is analyzed further and the regional and global impacts are investigated. It is found that particle size distribution is critically important: In regions where large, more absorbent dust particles are present, burdens are increased because of the enhanced heating aloft, which strengthens convection, whereas, in areas where smaller, more scattering particles dominate, the surface layers are stabilized and dust emissions are decreased. The consequent changes in dust load and particle size distribution when radiative effects are included make the annual mean global forcing more positive at the top of the atmosphere $\left(0.33\right.$ versus $\left.0.05 \mathrm{~W} \mathrm{~m}^{-2}\right)$. Impacts on the West African monsoon are also considered, where Saharan dust brings about a northward shift in the summertime intertropical convergence zone with increased precipitation on its northern side. This contrasts with results from some other studies, but the authors' findings are supported by recent observational data. They argue that the impacts depend crucially on the size distribution and radiative properties of the dust particles, which are poorly known on a global scale and differ here from those used in other models.
\end{abstract}

\section{Introduction}

Mineral dust aerosol is acknowledged as having a significant impact on the global climate system [Intergovernmental Panel on Climate Change (IPCC) Fourth Assessment Report; Forster et al. 2007]. Dust aerosol both absorbs and scatters incoming solar shortwave (SW) and outgoing thermal longwave (LW) radiation, and the importance of including these effects in both numerical weather prediction (NWP) and general circulation models (GCMs) has been recognized for many years (Haywood et al. 2005; Milton et al. 2008; Miller and Tegen 1998). The world's deserts are the main source of mineral dust aerosol; particles range in size from 0.01 to $100 \mu \mathrm{m}$ and have

Corresponding author address: Dr. M. J. Woodage, Department of Meteorology, Harry Pitt Building, 3 Earley Gate, University of Reading, Reading, Berkshire RG6 6AL, United Kingdom. E-mail: m.j.woodage@reading.ac.uk a variety of chemical compositions, shapes, and spectral properties (Pye 1987; Duce 1995; Sokolik et al. 1993, 1998). Dust particles are mobilized by complex small-scale processes when surface winds are sufficiently strong (see Gillette 1979; Pye 1987), and they are transported horizontally and vertically by turbulent, advective, and convective processes acting on a wide range of scales. This presents a difficult challenge for modeling because, on one hand, high spatial resolution is needed to simulate the emission processes realistically (e.g., Todd et al. 2008) but, on the other hand, global coverage is necessary estimate the full feedback effects because impacts can be seen far from the aerosol source regions (e.g., Menon et al. 2002). Few models are capable of fulfilling both these requirements; however, the atmospheric component of the U.K. High-Resolution Global Environmental Model (HiGEM) with horizontal resolution of $1.25^{\circ}$ longitude $\times 0.83^{\circ}$ latitude has been used for such experiments and has been shown to produce realistic simulations of the mineral dust 
TABLE 1. Particle sizes and their extinction coefficients and single scattering albedos at $550 \mathrm{~nm}$ for dust in HiGAM.

\begin{tabular}{lccc}
\hline \hline Dust division & Radius $(\mu \mathrm{m})$ & Extinction coef $\left(\mathrm{kg}^{-1}\right)$ & Single scattering albedo \\
\hline 1 (smallest) & $0.0316-0.1$ & 702.9 & 0.93 \\
2 & $0.1-0.316$ & 3663.1 & 0.98 \\
3 & $0.316-1.0$ & 995.7 & 0.95 \\
4 & $1.0-3.16$ & 265.6 & 0.80 \\
5 & $3.16-10.0$ & 79.0 & 0.64 \\
6 (largest) & $10.0-31.6$ & 24.3 & 0.55 \\
\hline
\end{tabular}

aerosol distribution and its associated radiative forcing (Woodage et al. 2010).

The question of the sign and magnitude of radiative forcing due to dust has been addressed by many authors. In one of the earliest papers, Carlson and Benjamin (1980) calculated the impact of dust in the Saharan air layer using a radiative transfer model and estimated the heating in the 1000-500-hPa layer to be about $1 \mathrm{~K} \mathrm{day}^{-1}$ for summertime conditions over the East Atlantic: a significant warming that could exceed in magnitude the atmospheric diabatic cooling rate. They found that, over the ocean, heating in the atmosphere is almost exactly balanced by a decrease in the net downward flux at the surface, thus increasing atmospheric stability but maintaining a steady state within the system: that is, not changing the values at the top of the atmosphere (TOA). Miller and Tegen (1998) used prescribed, seasonally varying concentrations of dust aerosol in an atmospheric GCM to estimate the climate response. They found a decrease in surface temperature of approximately $1 \mathrm{~K}$ beneath the dust cloud but not uniformly: In regions of deep convection cooling was absent, despite a large reduction in surface net radiation. It was suggested that this may be due to the linking of surface temperatures to the value at the emitting level above. Their estimate of the global, annual mean forcing was $-2.1 \mathrm{~W} \mathrm{~m}^{-2}$ at the surface and $-0.1 \mathrm{~W} \mathrm{~m}^{-2}$ at TOA [calculated from the reported seasonal values in Miller and Tegen (1998)]. In later work (Miller et al. 2004b), a fully interactive dust scheme was used in which dust emission was generated within the model rather than prescribed. Using a range of spectral values for the dust, they estimated the surface forcing to be between -2.47 and $-1.07 \mathrm{~W} \mathrm{~m}^{-2}$ and between 0.76 and $-0.82 \mathrm{~W} \mathrm{~m}^{-2}$ at TOA (for aerosol with more absorbent to more scattering properties, respectively).

While the surface forcing was always negative, the TOA value changed from negative to positive when more absorbent properties were assigned to the dust. A similar result was reported by Woodward (2001) using the Met Office Hadley Centre Atmosphere Model, version 3 (HadAM3); instead of changing the spectral properties of the dust, the contribution made to the total forcing by the different particle sizes was calculated. In that work, it was found that the surface global annual mean forcing was always negative and dominated by the medium-sized particles $(0.3-3.0 \mu \mathrm{m})$. At TOA the medium-sized particles again dominated the forcing with a positive impact; however, the smaller and larger particles had opposing impacts, with the smaller ones imposing a negative forcing and the larger ones producing a positive forcing. As particle size distribution affects the sign and magnitude of the radiative impact of the dust (Tegen and Lacis 1996), this demonstrates the importance of including the full range of particle sizes in the model in order to obtain a realistic estimate of the forcing.

In our earlier paper (Woodage et al. 2010), a highresolution atmospheric climate model with an embedded interactive mineral dust scheme similar to that of Woodward (2001) was described, and the global annual mean radiative forcing resulting from the dust was found to be $-1.14 \mathrm{~W} \mathrm{~m}^{-2}$ at the surface and $0.01 \mathrm{~W} \mathrm{~m}^{-2}$ at TOA. In that work, the atmospheric component of HiGEM (HiGAM) was run in paired experiments: one of which included dust radiative effects (active dust) and one excluded those effects (passive dust). Two pairs of experiments were run, forced by the Atmospheric Model Intercomparison Project phase 2 (AMIP-II) sea surface temperature dataset for the years 1983-2000. Dust radiative forcing was calculated from the passive dust runs, while comparison of the passive and active dust experiments enabled the feedback effects on the model climatology and the resulting dust emissions and burdens to be investigated. These full feedback effects, which occur when the dust is allowed to modify the climate, have not been considered as much the radiative forcing (defined by the IPCC as excluding feedback effects). Most studies of this kind have investigated the impacts on precipitation, especially the West African monsoon (e.g., Pérez et al. 2006; Yoshioka et al. 2007; Konare et al. 2008; Miller et al. 2004a,b; Solmon et al. 2008).

However, when full feedback effects are included, the dust itself may change significantly in terms of the load and particle size distribution. This topic has not received much attention in modeling studies but is important because both the dust loading and particle size distribution affect the sign and magnitude of the radiative 


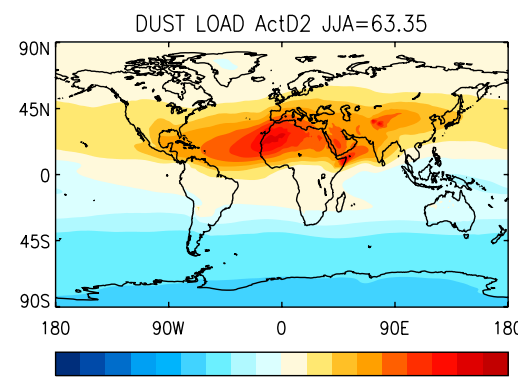

$\begin{array}{llllllllll}0 & 0.2 & 1 & 5 & 20 & 100 & 500 & 2000 & 1 e+4\end{array}$

DUST LOAD PasD2 JJA=50.51

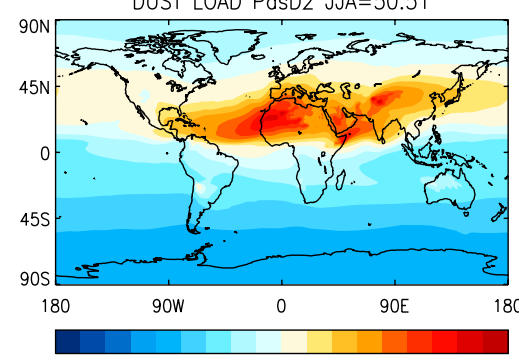

$\begin{array}{lllllllll}0 & 0.2 & 1 & 5 & 20 & 100 & 500 & 2000 & 1 \mathrm{e}+4\end{array}$

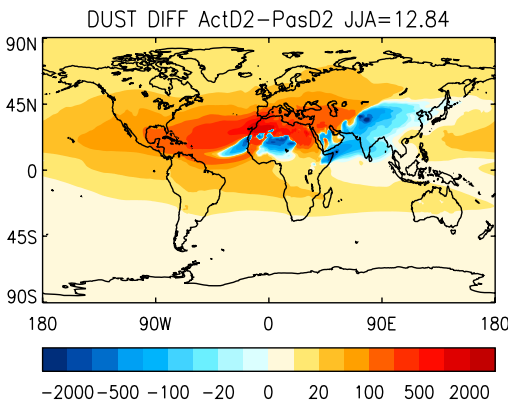

DUST LOAD ActD2 DJF=14.06

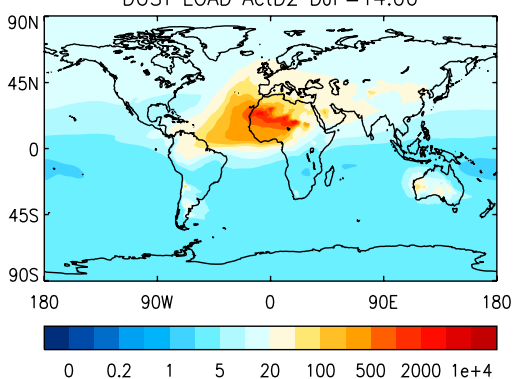

DUST LOAD PasD2 DJF=22.27

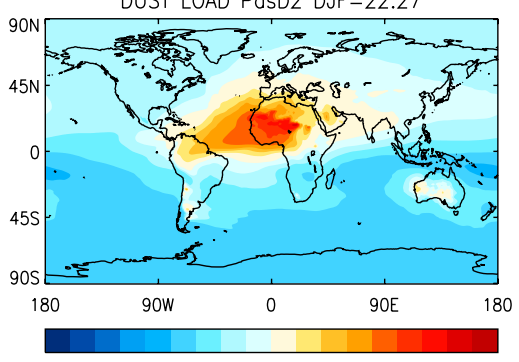

$\begin{array}{lllllllll}0 & 0.2 & 1 & 5 & 20 & 100 & 500 & 2000 & 1 \mathrm{e}+4\end{array}$

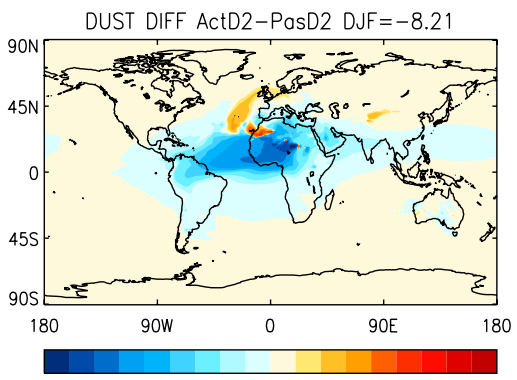

$-2000-500-100 \quad-20 \quad 0 \quad 20 \quad 100 \quad 500 \quad 2000$

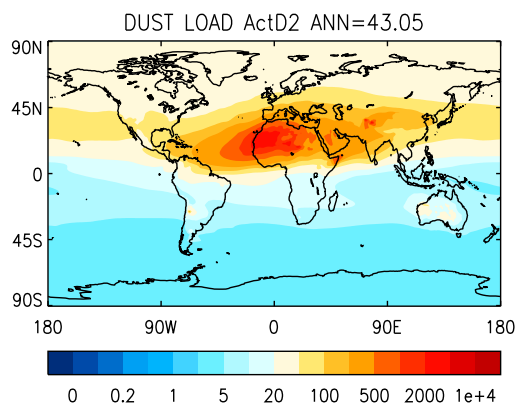

DUST LOAD PasD2 ANN=36.63

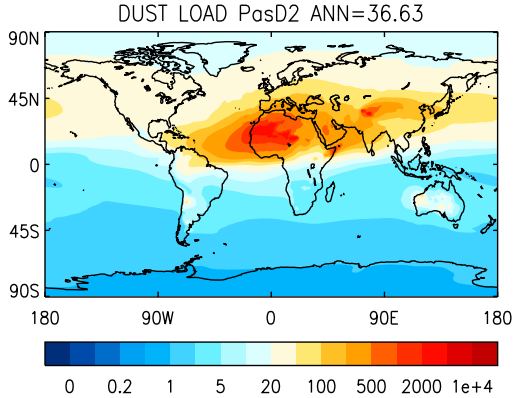

DUST DIFF ActD2-PasD2 ANN=6.42

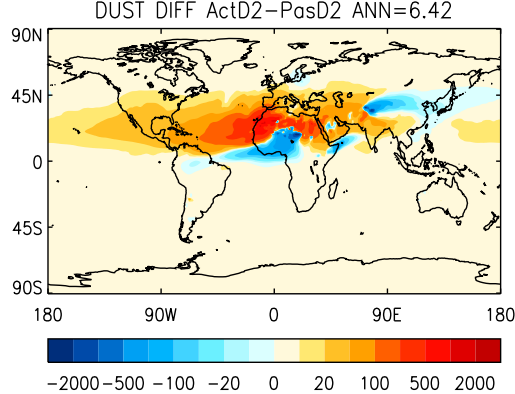

FIG. 1. The 18-yr mean dust column loadings $\left(\mathrm{mg} \mathrm{m}^{-2}\right.$ ) for (left) JJA, (center) DJF, and (right) ANN for (top) ActD2 and (middle) PasD2 experiments. (bottom) ActD2 - PasD2 differences are shown. Global totals in captions are in terragrams.

impact of the dust, as noted above. Miller et al. (2004b) used the National Aeronautics and Space Administration (NASA) Goddard Institute for Space Studies (GISS) atmospheric GCM to calculate the surface and TOA radiation flux differences between active and passive dust experiments. They termed these differences the flux anomalies and found that in their experiments the surface SW flux anomaly was $-1.84 \mathrm{~W} \mathrm{~m}^{-2}$ compared with a surface forcing of $-1.64 \mathrm{~W} \mathrm{~m}^{-2}$, so the feedback effect was to intensify the surface forcing. The authors argued that this could be due to an increase in cloud cover, but there could also be a contribution because of a change in the dust load itself, which was not investigated.

Woodage et al. (2010) reported that the experiments with active dust had higher annual mean burdens than those with passive dust and noted that this finding of a positive feedback was unusual (e.g., Perlwitz et al.
2001; Miller et al. 2004a; Pérez et al. 2006). Here we examine the reasons for this and also analyze the impact on other aspects of the climate, particularly that of northern West Africa, which is influenced by the Sahara, the largest source of dust in the world. The climatology of that region in boreal summer is dominated by the movement and intensity of the intertropical convergence zone (ITCZ), which marks the region separating the hot, dry air of the Sahara to the north from the cooler, moist, southwesterly airflow to the south. This surface convergence zone was classically thought to be directly associated with the intense precipitation of the West African monsoon (WAM), but Nicholson (2009) suggests that the rain belt is more closely associated with a large core of ascent between the African easterly jet (AEJ) and higher-level tropical easterly jet (TEJ). Nicholson also proposed that the monsoon has 
TABLE 2. Annual and seasonal global mean dust loadings for the ActD2 and PasD2 experiments with the relative proportions (by mass) of small (divisions 1 and 2), medium (divisions 3 and 4), and large (divisions 5 and 6 ) radius particles. Standard deviations of the ANN total loadings are in parentheses.

\begin{tabular}{llcrrrr}
\hline \hline & & \multicolumn{2}{c}{ Mean dust load (Tg) } & & \multicolumn{2}{c}{ Dust mass fraction } \\
\cline { 3 - 3 } \cline { 5 - 6 } Expt & Season & All & & Small & Medium & Large \\
\hline ActD2 & ANN & $43.05(13.7)$ & & $9 \%$ & $59 \%$ & $33 \%$ \\
& DJF & 14.06 & $14 \%$ & $51 \%$ & $35 \%$ \\
& MAM & 70.57 & $2 \%$ & $66 \%$ & $31 \%$ \\
& JJA & 63.35 & $8 \%$ & $56 \%$ & $36 \%$ \\
& SON & 23.73 & $28 \%$ & $47 \%$ & $25 \%$ \\
PasD2 & ANN & $36.63(9.0)$ & & $11 \%$ & $52 \%$ & $37 \%$ \\
& DJF & 22.27 & $5 \%$ & $70 \%$ & $25 \%$ \\
& MAM & 42.12 & $2 \%$ & $64 \%$ & $34 \%$ \\
& JJA & 50.51 & $10 \%$ & $39 \%$ & $51 \%$ \\
& SON & 31.24 & $28 \%$ & $45 \%$ & $27 \%$ \\
\hline
\end{tabular}

a bimodal state, associated with either wet or dry conditions in the Sahel, contributing to the interannual variability of the rainfall. The AEJ (e.g., Cook 1999) is an intense but relatively small-scale geostrophic wind with core strength of $10-20 \mathrm{~m} \mathrm{~s}^{-1}$ at a height of 600 $700 \mathrm{hPa}$, located between $10^{\circ}$ and $20^{\circ} \mathrm{N}$, extending from central Africa to the West African coast. It is highly variable in space, time, and strength, and Parker et al. (2005) note that it is a serious challenge for climate and weather prediction models to simulate this feature. Mineral dust aerosol can influence the temperature gradient driving this wind, thereby impacting on the strength and position of the jet, as shown by Tompkins et al. (2005). In that work, a more accurate forecast of the AEJ was achieved in the European Centre for MediumRange Weather Forecasts (ECMWF) model by using more realistic representation of the aerosol direct radiative forcing. In this work, we will investigate how these features are affected by dust aerosol in HiGAM.

The rest of this paper is organized as follows: In the next section we briefly describe the model used and the experiments run. In section 3 we report the results, including (i) comparison of the dust burdens and emissions in the active and passive dust experiments; (ii) analysis of the dust radiative forcing and the radiative anomalies at the surface and top of the atmosphere; and (iii) examination of the impact of the dust on regional climatologies including the ITCZ, AEJ, atmospheric stability, and precipitation in different areas. In section 4 the results are discussed, and in section 5 conclusions are drawn and suggestions are made for future work.

\section{Model and experiments}

The atmospheric component of the U.K. HiGEM (Shaffrey et al. 2009) was used in these experiments, forced by AMIP-II sea surface temperatures (SSTs) for 1983-2000 (dataset online at http://www-pcmdi.llnl.gov/ projects/amip/AMIP2EXPDSN/BCS/bcsintro.php). This model includes a fully interactive mineral dust aerosol scheme based on that of Woodward (2001), with six particle size bins in the range of $0.03-30-\mu \mathrm{m}$ median radius, covering clay $(0-1 \mu \mathrm{m})$, silt $(1-25 \mu \mathrm{m})$, and sand $(>25 \mu \mathrm{m})$. A dust parent soil ancillary file (interpolated from Wilson and Henderson-Sellers 1985) determines the fractions and relative masses of clay, silt, and sand available at the surface, and it is assumed that to a first approximation the size distribution of the dust flux is similar to that of the parent soil. Dust is mobilized when the friction velocity exceeds a threshold value $U_{t}^{*}$, which is a function of the representative particle diameter $D_{\text {rep }}$ (in meters) and soil moisture content $W$ (in kilograms per square meter for top $10-\mathrm{cm}$ soil layer) given by

$$
U_{t}^{*}=A \log _{10}\left(D_{\mathrm{rep}}\right)+B W+C,
$$

where $A=-0.2$ and $B$ and $C$ are constants determined empirically (by "trial and error" method). The magnitude of the dust flux is a function of the cube of the friction and threshold friction velocities, so the dust burden in the model is very sensitive to the choice of the values of $B$ and $C$ in Eq. (1). In sensitivity experiments to tune these parameters it was found that setting $B=0.15$ and $C=-0.7$ gave the most realistic dust loadings in HiGAM when compared with observations and other models (see Woodage et al. 2010 for further details). The expression $A \log _{10}\left(D_{\text {rep }}\right)+C$ may be considered as the dry soil threshold friction velocity and is a straightline fit to the relevant part of the $U_{t}^{*}$ versus particle diameter curve from Bagnold (1941) (see Woodward 2001).

HiGAM is a nonhydrostatic gridpoint model with horizontal resolution of $1.25^{\circ}$ longitude $\times 0.83^{\circ}$ latitude and 38 levels in the vertical. It has a semi-Lagrangian advection scheme, prognostic cloud physics, and shallow and deep convection parameterizations. There is a land surface exchange scheme with boundary layer mixing of surface fluxes, and the radiation scheme is the two-stream Edwards-Slingo code (Edwards and Slingo 1996). The dust aerosol in the model is subject to advection, mixing by turbulence in the boundary layer and by convection, dry and wet deposition, and gravitational settling. Deposition processes are particle size-dependent; wet deposition due to precipitation scavenging within and below cloud is represented by a first-order removal rate in which the scavenging coefficient increases with particle size. Dry deposition through gravitational settling takes place throughout the atmosphere; in the boundary layer it is combined 


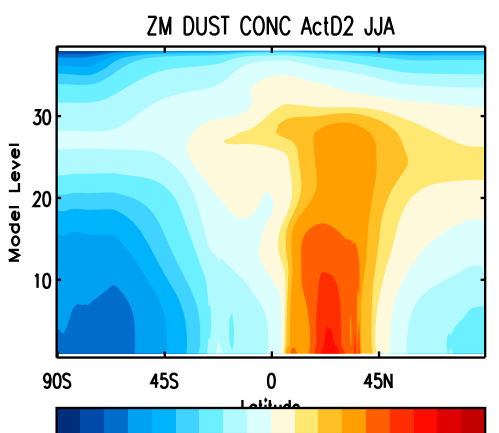

$\begin{array}{lllllllll}0 & 0.02 & 0.1 & 0.5 & 2 & 10 & 50 & 200 & 1000\end{array}$
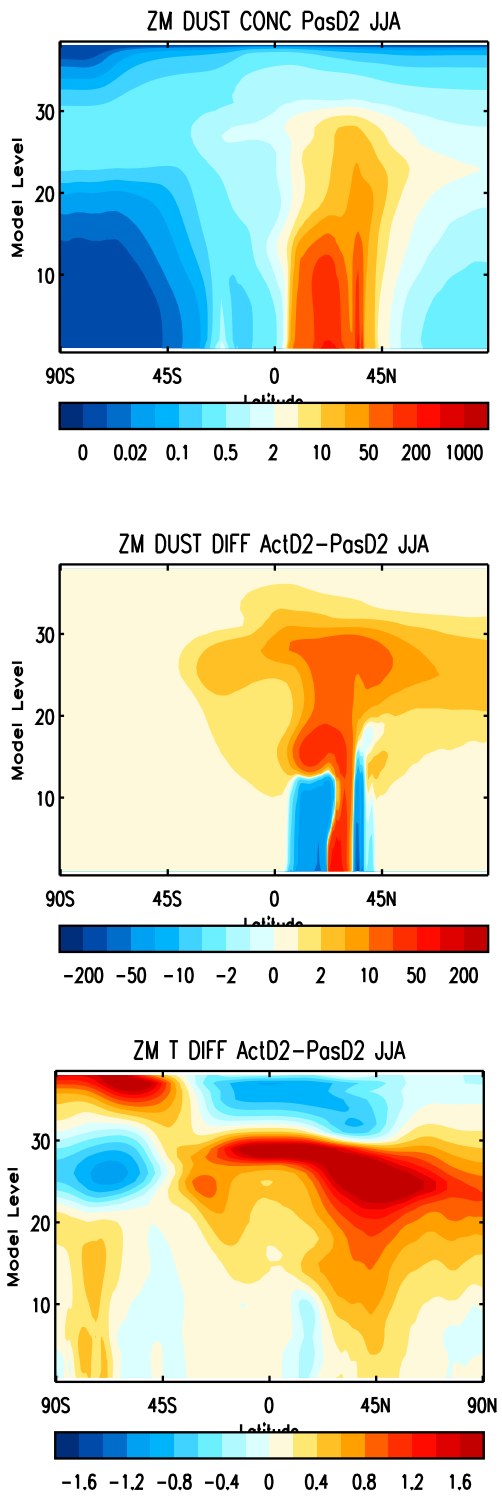

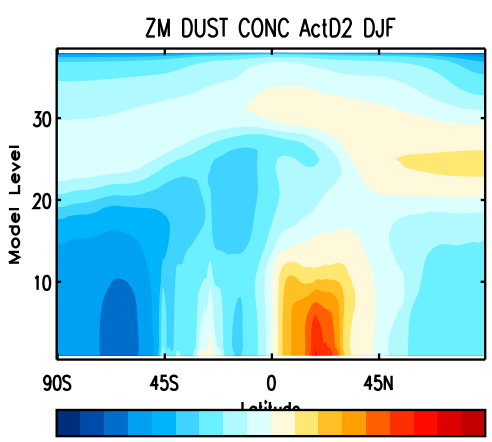

$\begin{array}{lllllllll}0 & 0.02 & 0.1 & 0.5 & 2 & 10 & 50 & 200 & 1000\end{array}$
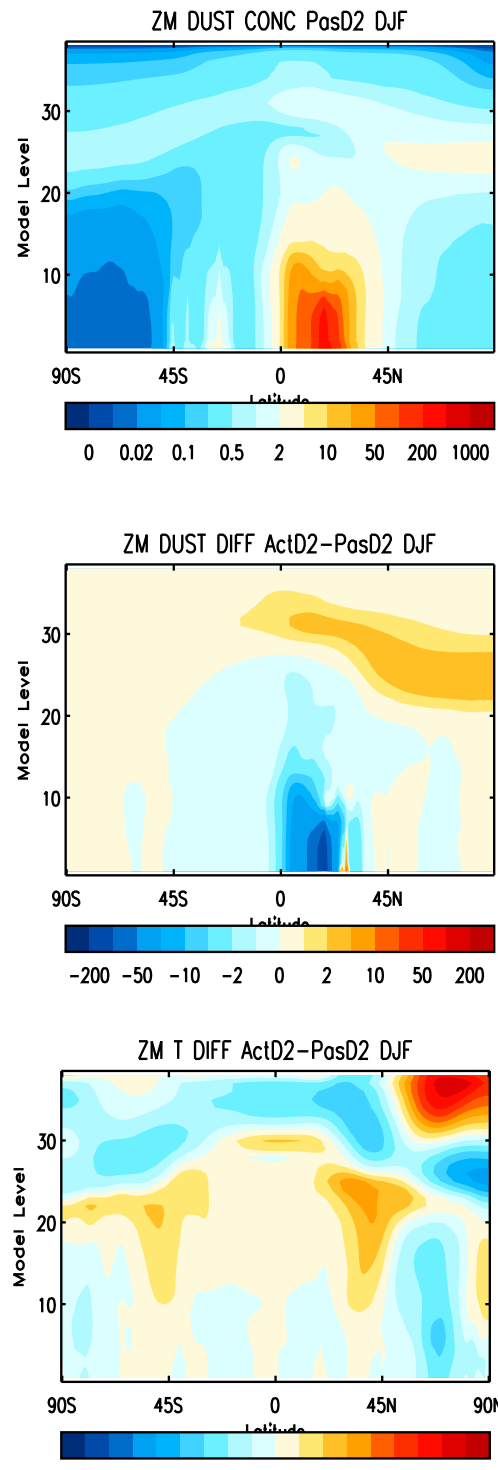

$\begin{array}{lllllllll}-1.6 & -1.2 & -0.8 & -0.4 & 0 & 0.4 & 0.8 & 1.2 & 1.6\end{array}$
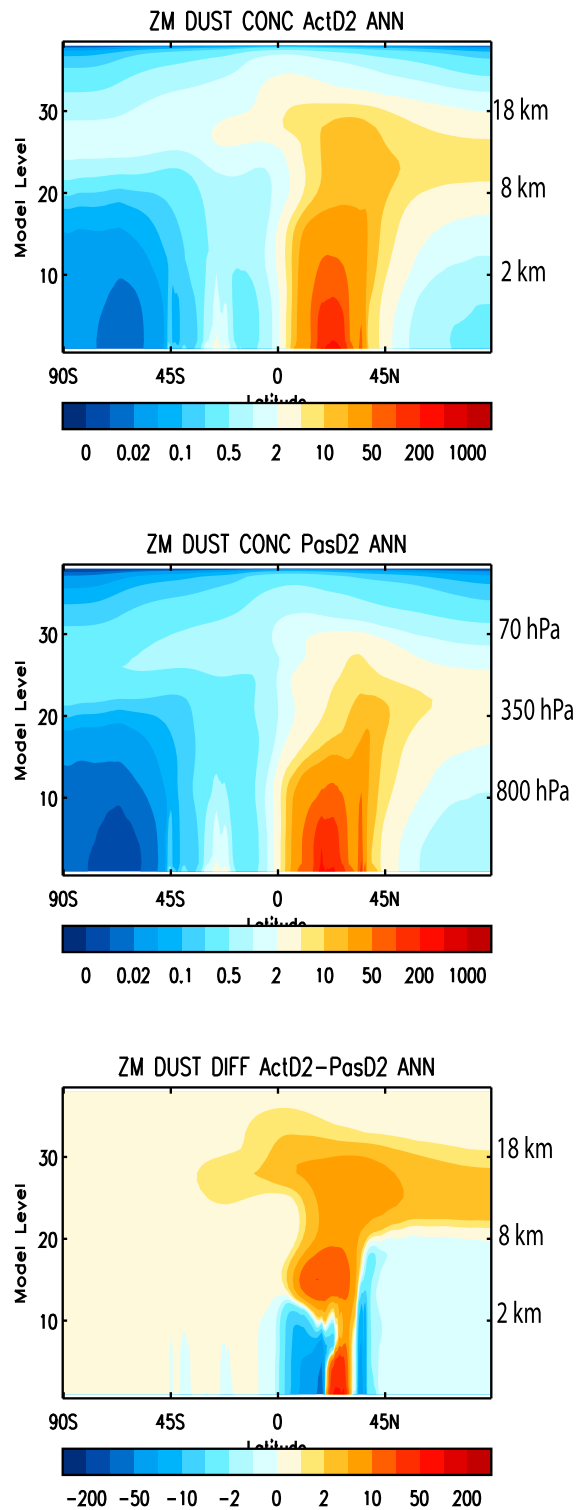

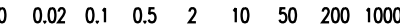

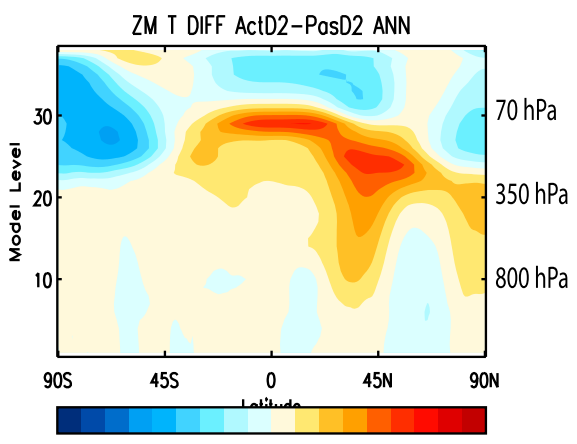

$\begin{array}{lllllllll}-1.6 & -1.2 & -0.8 & -0.4 & 0 & 0.4 & 0.8 & 1.2 & 1.6\end{array}$

FIG. 2. The 18-yr zonal mean dust mass concentrations $\left(\mathrm{mg} \mathrm{kg}^{-1}\right.$ ) for (left) JJA, (center) DJF, and (right) ANN for (top) ActD2, (middle top) PasD2, and (middle bottom) their differences. (bottom) The corresponding zonal mean temperature differences. Model levels 10, 20, and 30 are approximately equivalent to heights $2 \mathrm{~km}(800 \mathrm{hPa}), 8 \mathrm{~km}(300 \mathrm{hPa})$, and $18 \mathrm{~km}(70 \mathrm{hPa})$. 

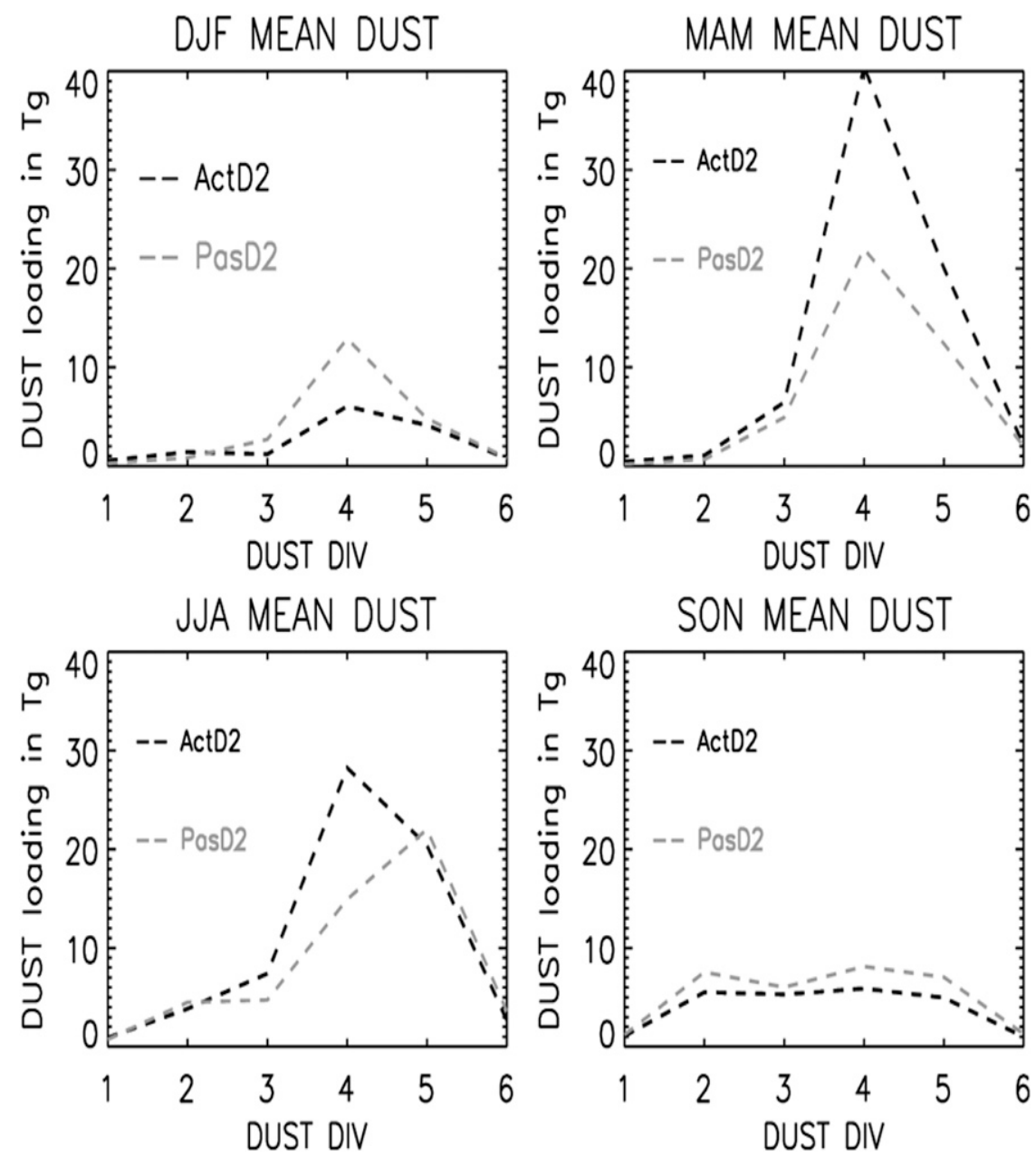

FIG. 3. Global seasonal mean dust loadings for each dust size division for the active (black) and passive (gray) dust experiments.

with turbulent mixing using a resistance analog method where deposition velocities are treated as inverse resistances (see Woodward 2001 for details). Radiative feedback is via the direct effect only (scattered and/or absorbed solar and thermal radiation) for the active dust experiments; microphysical effects are not incorporated. The radiative properties of dust are modeled assuming spherical particles, with refractive indices that are designed to be globally representative and are based on the median of results shown in Sokolik et al. (1993, 1998), Carlson and Benjamin (1980), and Deepak and Gerber (1983). Table 1 summarizes the spectral properties (extinction coefficient and single scattering albedo) of each dust size division used in the model; further details can be found in Woodward (2001). Some evidence (e.g., Balkanski et al. 2007) suggests that the values used here may be too high in the visible for Saharan dust, causing it to be too absorbent, and this will be taken into account when analyzing the results. However, recent observations from the Sahara (Ryder et al. 2013) have found much larger aerosol particles with higher absorption than previously recorded, adding credence to our model values. Two active and two passive dust experiments were run as described in Woodage et al. (2010). The results for the two pairs were qualitatively similar, so we restrict our analysis in this work to the second pair, retaining the names ActD2 and PasD2 to aid comparison with our earlier work. Radiative forcing was calculated from PasD2 by using the "double radiation call" method (Woodward 2001) in which the SW and LW radiative increments due to dust are calculated but not used when the model is advanced (thus eliminating feedbacks). Full feedback effects were found by differencing ActD2 and PasD2; differences in the annual mean global dust burdens (see section 3a) were found 

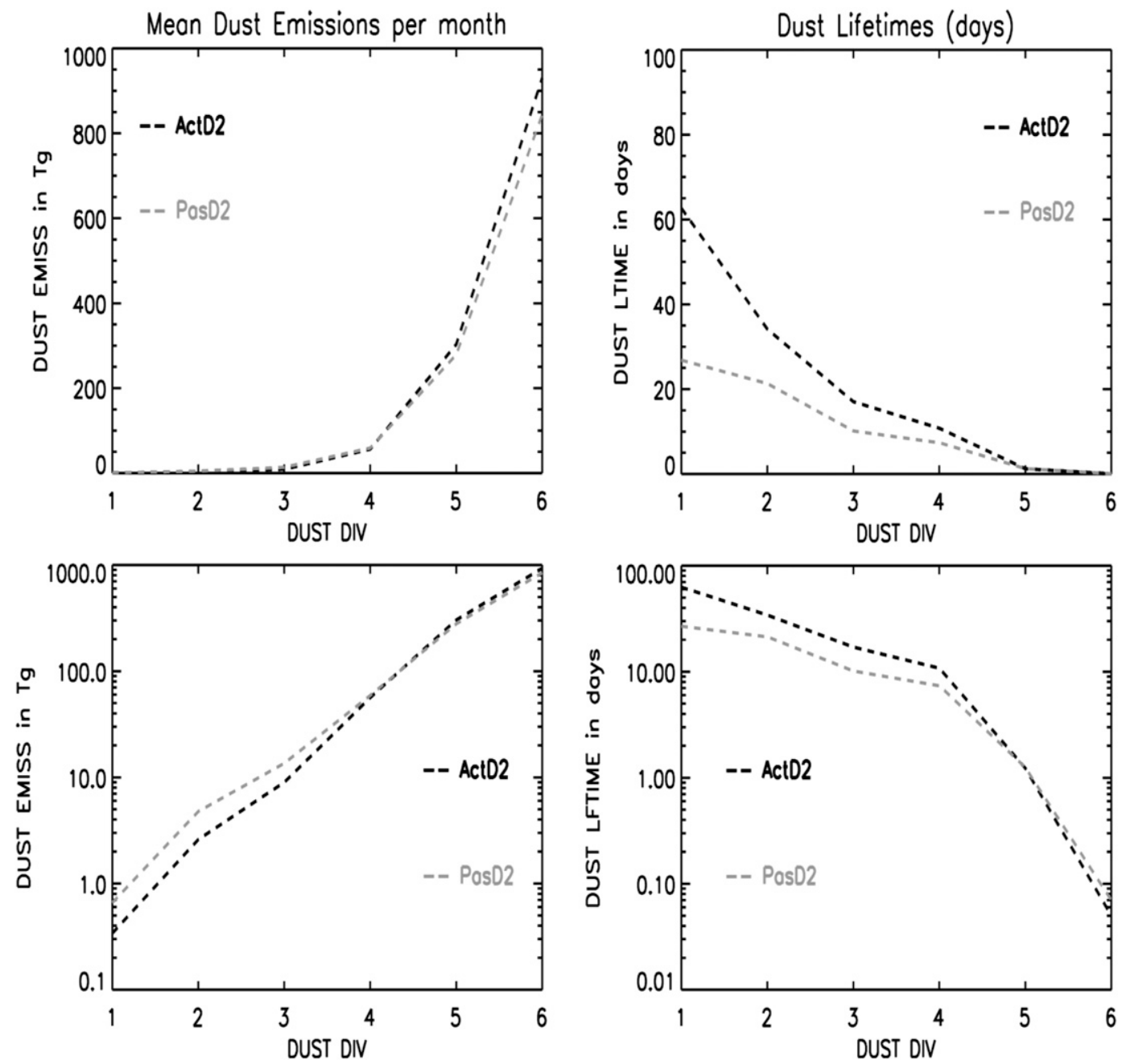

FIG. 4. (left) Annual mean dust emissions and (right) dust lifetimes for each dust size division for the active (black) and passive (gray) dust experiments. (top) Linear scale is on vertical axis. (bottom) Plots have log scale on vertical axis.

to be significant at the $98 \%$ level $(p=0.02)$ and differences in the WAM precipitation (section $3 \mathrm{c}$ ) were significant at better than $99 \%\left(p=3.54 \times 10^{-8}\right)$ using paired $t$ tests.

\section{Results}

\section{a. Dust loadings, emissions, and particle size distributions}

Figure 1 shows the June-August (JJA), DecemberFebruary (DJF), and annual (ANN) 18-yr mean column dust loadings for ActD2 (top), PasD2 (middle), and their differences (bottom). The model dust loadings have been verified against available satellite and ground-based observations in Woodage et al. (2010) so they will not be repeated here, but we note that the spatial and temporal distribution of dust is simulated realistically, even though the global total burdens are rather high. It is evident from the difference plots in Fig. 1 (and also from the data in Table 2) that the global total dust loading in ActD2 is greater than in PasD2 for JJA and ANN but smaller in DJF. However, there are regional variations: for example, in JJA the dust loadings over India, China, and central North Africa are reduced in ActD2 despite the increase elsewhere. In DJF, loadings are increased in ActD2 over the northwestern Sahara, Canary Islands, and the western Atlantic but decreased elsewhere. These differences may be due to changes in dust emissions, deposition, and/or transport. Figure 2 displays the corresponding zonal mean vertical cross sections of dust mass concentration 

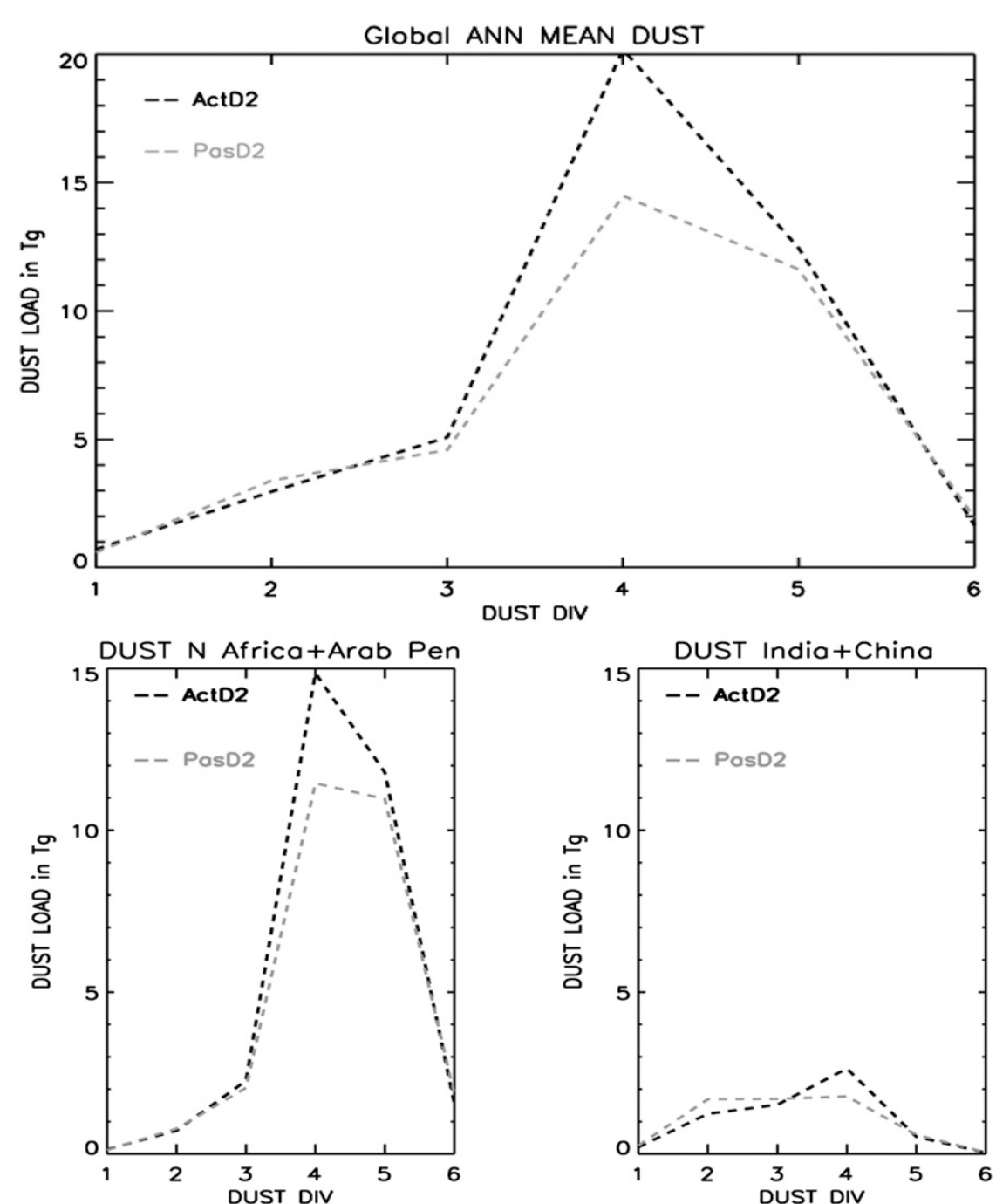

FIG. 5. (top) Global and (bottom) regional annual mean dust loading for each dust size division (1-6) for the active (black) and passive (gray) dust experiments. (bottom left) Loadings for the global sector containing North Africa and the Arabian Peninsula $\left(60^{\circ} \mathrm{W}-60^{\circ} \mathrm{E}, 0^{\circ}-90^{\circ} \mathrm{N}\right)$ and (bottom right) loadings for sector containing India and China $\left(60^{\circ} \mathrm{E}-180^{\circ}, 0^{\circ}-90^{\circ} \mathrm{N}\right)$.

(in milligrams per kilogram), which shows that the dust is lofted higher in the atmosphere in ActD2, suggestive of increased vertical motion, especially in JJA. This is supported by the temperature difference plots shown in the bottom panels of Fig. 2, showing that in ActD2 there is a marked heating aloft in the Northern Hemisphere that extends to the surface at approximately $45^{\circ} \mathrm{N}$ in JJA. To explore these results further, we now consider how the dust size distributions for the two experiments change during the year.

Table 2 shows the annual and seasonal global mean dust loadings for the active and passive dust experiments with the relative proportions (by mass) of small $(0.03-0.32-\mu \mathrm{m})$, medium $(0.32-3.16-\mu \mathrm{m})$, and large $(3.16-31.6-\mu \mathrm{m})$ radius particles. The seasonal range for the total dust loading is higher for the active dust case by a factor of 2 , although it has less variation in the particle size distribution than the passive dust experiment. This can be seen in more detail in Fig. 3, which shows the loadings of dust in each size division for each season. The relative proportions (by mass) of small, medium, and large particles for the two experiments are similar in March-May (MAM), when both have the minimum proportion of the smallest particles $(2 \%)$, and September-November (SON), when both have the maximum proportion of the smallest particles (28\%). In DJF and JJA, however, the experiments differ considerably: for DJF, PasD2 has a much higher proportion of medium-sized particles than ActD2 (70\% and 51\% 
DIFF ActD2-PasD2 ANN MEAN DUST EMISS

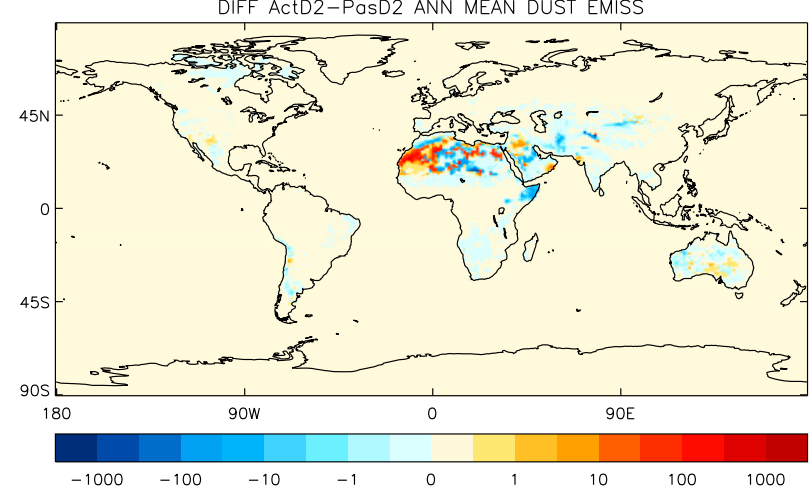

FIG. 6. Differences in annual mean dust emissions between the active and passive dust experiments $\left(\mu \mathrm{g} \mathrm{m}^{-2}\right.$ month $\left.^{-1}\right)$.

respectively), at the expense of both small and large-sized particles. In JJA the reverse is true, with PasD2 having a smaller proportion of medium-sized particles $(39 \%$ and $56 \%$ respectively) and a higher proportion of large-sized particles than ActD2. This has implications for the dust radiative forcing in PasD2 and the feedback anomalies in ActD2 through the year because the spectral properties of the particles vary with size; this is discussed further in section $3 b$.

The dust loadings in the atmosphere are a product of the emissions and lifetimes of the particles (particles are removed by wet and dry deposition and gravitational settling). Figure 4 shows the annual monthly mean emissions and lifetimes of the particles for each size division, and we see that the largest particles have the highest emissions (by mass) and the shortest lifetimes, while the smallest particles have the lowest emissions and the longest lifetimes. This leaves the medium-sized particles to make up the bulk of the dust mass in the global atmosphere. Note that the emissions plotted here include those which are deposited back to the surface within the same model time step (because of the way the model diagnostics are produced), so the size distribution seen by the model contains a smaller mass of large particles than this plot suggests; however, as this is the same for both experiments the comparisons are valid. The seasonal changes in the size distribution of the dust burden are explained as follows: global dust emissions of all particle sizes are highest in boreal spring and summer as the ITCZ moves northward across the equator to the world's main desert areas. While the larger particles have short lifetimes (hours or a few days), the smaller particles remain in the atmosphere for much longer (up to 60 days; see Fig. 4) so that the particle size distribution of the dust remaining in the atmosphere is shifted toward the smaller sizes in SON.

Note that the active dust experiment has fewer emissions (approximately half) in the smallest size division but they have a longer lifetime (roughly double) than in the passive dust experiment. Conversely, the active dust experiment has slightly more emissions of the largest particle size but they have a shorter lifetime than in the passive dust experiment. There are also regional differences, as shown in Fig. 5, which shows the particle size distribution of the annual mean dust load globally, over North Africa and the Arabian Peninsula (NA-AP), and over India and China (IN-CH). Although the peak mass is in size division $4(1-3 \mu \mathrm{m})$, there is a much higher proportion of large particles over NA-AP than over IN-CH. It is also evident that the dust over NA-AP makes up most of the global total load for the larger particles (divisions 4-6), while IN-CH have most of the smallest particles (divisions 1 and 2); particles in division 3 are evenly split between the two regions. A consistent result in all the figures shown so far is that for the active dust experiment the dust load is increased in regions and at times of the year when large particles dominate; if smaller particles dominate, then loads are decreased. Figure 6 shows the annual mean differences in total dust emissions between the active and passive dust experiments; note that, in ActD2, emissions over North Africa are generally increased, whereas over India and China they are mainly decreased. Figure 7 shows that, in our model, emissions over NA-AP make up nearly the entire global total of the largest particle emissions, whereas nearly all of the smallest particle emissions come from IN-CH. It also confirms that, in ActD2, total emissions are increased over NA-AP but decreased over IN-CH. Therefore it appears that the larger particles act to increase emissions but smaller ones act to decrease emissions. We investigate this further in the next section by examining the spectral properties of the dust size divisions and their radiative impacts.

\section{b. Dust radiative forcing and radiative anomalies}

Figure 8 shows the extinction coefficient and single scattering albedo (SSA) in each wave band for the different dust size divisions in HiGAM. The small and medium particles (divisions 1-4: $0.03-3.16 \mu \mathrm{m}$ ) are the most scattered and absorbed, especially in the shortwave bands; however, the activity of the largest particles is significant in the longwave ( $>4000-\mathrm{nm}$ wavelength). This becomes important over source areas where large particles are abundant, especially at night, when there is no SW activity at all, and dust can act to destabilize the temperature profile by enhancing the atmospheric cooling to the surface (see Allan et al. 2011). The relative importance of the LW effects can be seen in Fig. 9, which compares annual mean dust radiative forcing from experiment PasD2 over the whole globe, for the 

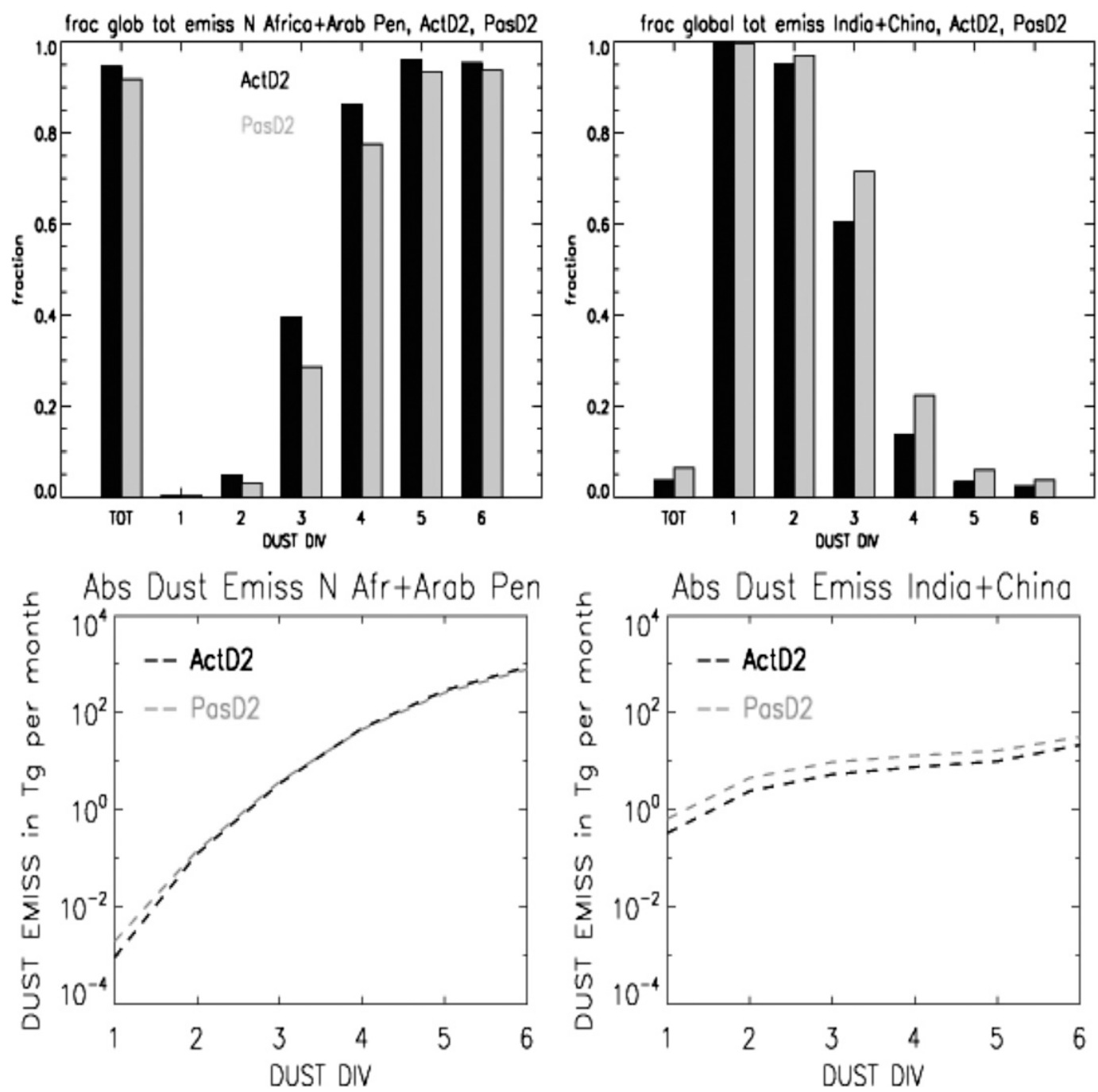

FIG. 7. Regional annual mean dust emissions as (top) a fraction of the global total and (bottom) absolute values for each dust size division (1-6). (left) Loadings for the global sector containing North Africa and the Arabian Peninsula $\left(60^{\circ} \mathrm{W}-60^{\circ} \mathrm{E}, 0^{\circ}-90^{\circ} \mathrm{N}\right)$ and (right) loadings for sector containing India and China $\left(60^{\circ} \mathrm{E}-180^{\circ}, 0^{\circ}-90^{\circ} \mathrm{N}\right)$. Note log scale in (bottom).

northwest Africa region (NWAF; $20^{\circ} \mathrm{W}-20^{\circ} \mathrm{E}, 0^{\circ}-40^{\circ} \mathrm{N}$ ), and for India and China (INCH; $\left.60^{\circ}-110^{\circ} \mathrm{E}, 10^{\circ}-50^{\circ} \mathrm{N}\right)$ at the surface (SFC), at the top of the atmosphere, and in the atmospheric column (ATM). Figure 10 shows the geographical distribution of the same forcings over the whole globe; all forcings are greatest over NWAF because dust is more abundant there. Note that, in ATM, any LW cooling due to dust is outweighed by the SW warming, creating a net heating in the atmosphere both globally and regionally. (However, at night, the LW cooling can be significant regionally, as noted above.)

Note also that, at TOA, SW dust forcing is positive over NWAF but negative over INCH. This is because the dust appears dark relative to the surface of the NWAF region, where there are more of the larger particles (see Fig. 5) and the mean surface albedo is 0.27 in HiGAM; but dust appears bright relative to the surface of the INCH area, where there are more of the smaller particles and the mean surface albedo is 0.20 . Also, at TOA, the LW forcing is positive everywhere and particularly significant over NWAF; this was also shown in Woodage et al. (2010), where the outgoing LW radiation (OLR) from HiGAM was compared with Geostationary Earth Radiation Budget (GERB) data (Harries et al. 2005) over the Sahara in July. It was shown that, when dust was included in HiGAM, a better match to the observed OLR was made.

Inclusion of the full range of particle sizes is therefore crucial for feedback studies. Woodward (2001) pointed 

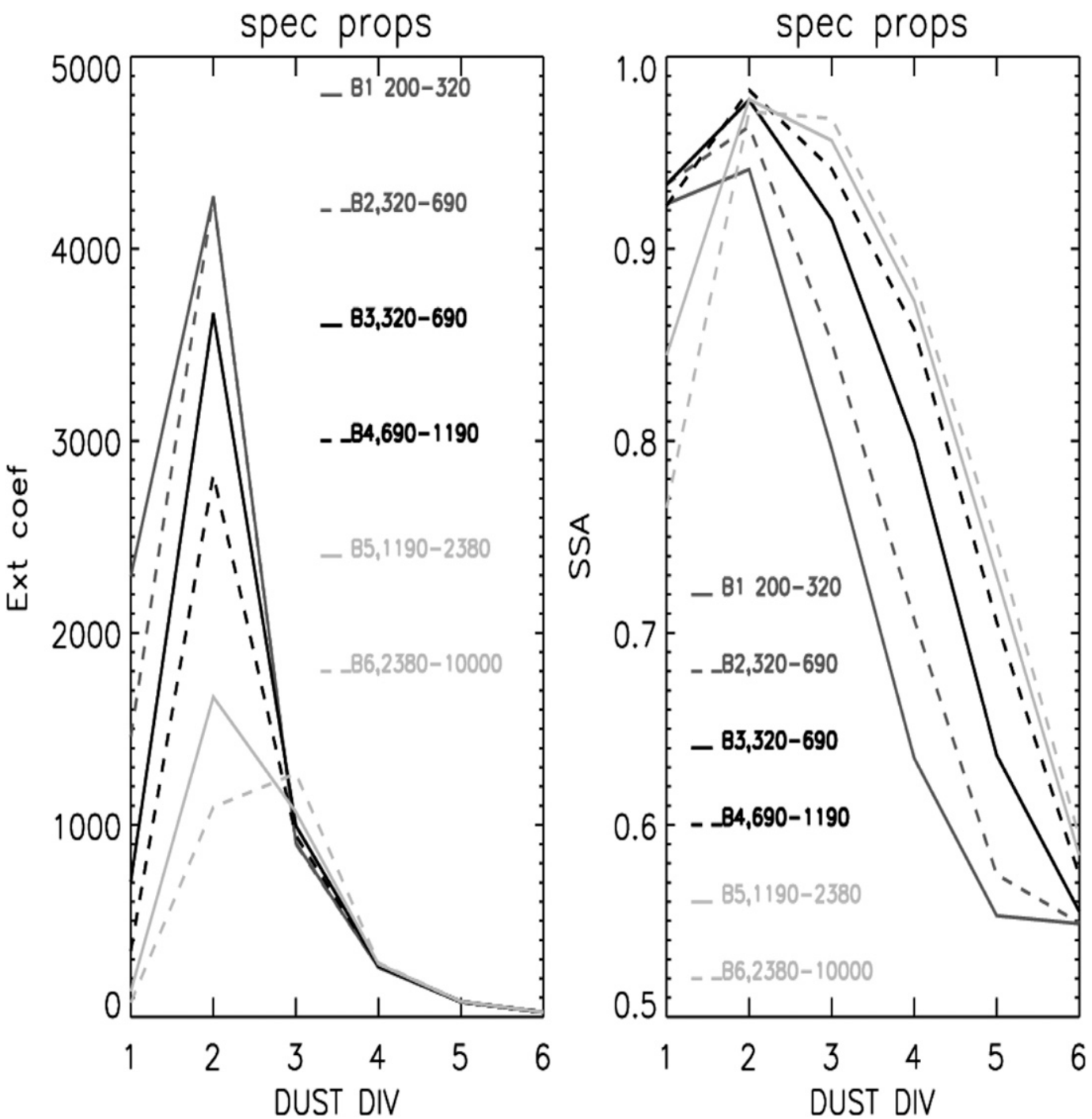

FIG. 8. Spectral properties of each dust size division (1-6) in HiGAM for each wave band (B1-B6; wavelengths in nanometers): (left) The extinction coefficients and (right) SSA.

this out and showed that in her study with HadAM3 the surface global annual mean forcing is always negative and dominated by the medium-sized particles $(0.3-$ $3.0 \mu \mathrm{m})$. At TOA, the medium-sized particles again dominated the forcing with a positive impact; however, the smaller and larger particles had opposing impacts, with the smaller ones imposing a negative forcing and the larger ones imposing a positive forcing. Although we did not repeat Woodward's experiment here, our model has the same basic dust scheme and we would expect similar reasoning to be valid. Woodward had approximately $5 \%$ of particles in the small range, $70 \%$ in the medium range, and $25 \%$ in the large range [estimated from Fig. 6 of Woodward (2001)]. This is the same as in our passive dust run in DJF; otherwise, our experiments have a smaller proportion of medium-sized particles.
Table 3 shows the radiative forcing due to dust in the passive dust experiment and the feedback anomalies derived from differencing the active and passive dust experiments for ANN, DJF, and JJA. We have also shown the values normalized by the dust burdens because the latter vary between seasons and experiments. We note particularly that the net TOA forcing in DJF is positive in PasD2 but negative in the ActD2 - PasD2 anomaly; this is because of the higher proportion of smaller particles in ActD2 in DJF (14\% versus 5\%), as mentioned in section 2. We also note that in JJA the SW TOA forcing is negative in PasD2 but positive the ActD2 - PasD2 anomaly; this may be due to the slightly higher proportion of smaller particles in PasD2 (10\% versus $8 \%)$ but may also be because dust is lofted higher in ActD2 (see Fig. 2) and more will be above clouds, reducing their reflectivity back to space. 


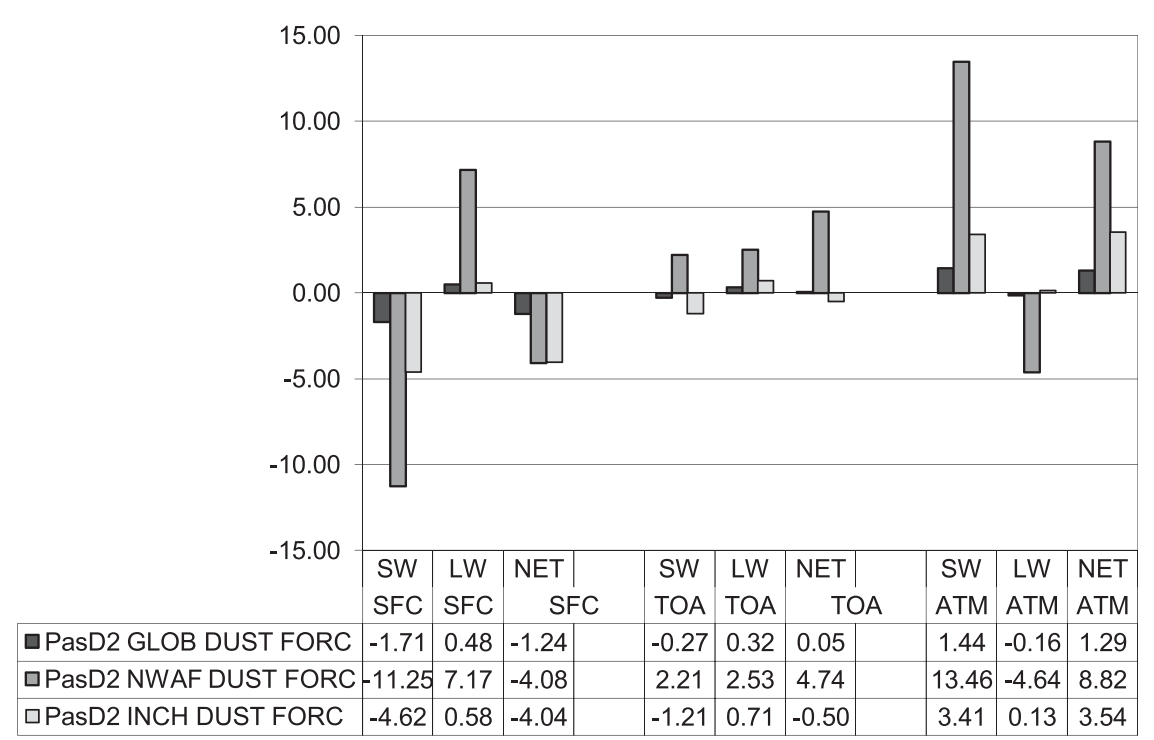

FIG. 9. Annual mean dust radiative forcing $\left(\mathrm{W} \mathrm{m}^{-2}\right)$ at the surface, at the top of the atmosphere, and in the atmospheric column (ATM = TOA - SFC) for the whole globe (black), for NWAF (dark gray), and for INCH (light gray). Positive values indicate a warming, and negative values show a cooling.

Figure 11 shows the geographical distribution of the annual mean dust radiative anomalies, obtained by differencing ActD2 and PasD2. The changes due to the cloud differences between ActD2 and PasD2 are evident in the relatively dust-free regions, such as over the Southern Hemisphere oceans and Indonesia, and the total radiative anomaly comprises changes due to both dust and cloud. The annual mean net dust forcing for PasD2 is more negative than the ActD2 dust anomaly both at the surface $\left(-1.24\right.$ versus $\left.-1.06 \mathrm{~W} \mathrm{~m}^{-2}\right)$ and at TOA ( 0.05 versus $\left.0.33 \mathrm{~W} \mathrm{~m}^{-2}\right)$. This is mainly because the passive dust experiment has a higher proportion of the smallest particles than the active dust experiment ( $11 \%$ versus $9 \%$ ); however, changes in cloud forcing in ActD 2 could also make a contribution. Table 4 compares the global annual mean precipitation, cloud fraction, and cloud forcing (calculated as the difference between the all-sky and clear-sky SW and LW radiative increments) for the passive and active dust experiments. This confirms that cloud impacts on the forcing are small in the global mean, with no overall change in the global cloud fraction and $<2 \%$ increase in the net cloud forcing at SFC and TOA. When feedbacks are included the global annual mean precipitation is slightly reduced (by $1 \%$ ); however, regional changes are much greater than this: for example, over the northwest Africa region $\left(20^{\circ} \mathrm{W}-10^{\circ} \mathrm{E}, 0^{\circ}-30^{\circ} \mathrm{N}\right)$ there is an increase of $23 \%$ in annual mean precipitation for ActD2. This will be discussed in the next section along with other aspects of the impact of dust forcing on the climatology of different regions.

\section{c. Impact of dust forcing on regional climatologies}

Figure 12 shows the summertime (JJA) climatology of North Africa and the tropical Atlantic Ocean for ActD2 and PasD2, and their differences. We show the 700-hPa temperature (T700), the OLR, the cloud fraction (CLOUD), the mean sea level pressure (MSLP), and the precipitation rate (PPTN). The location of the dust for JJA in the region can be seen in Fig. 1. Looking at the difference plots in Fig. 12 (right), we see that the dust induces a warming at $700 \mathrm{hPa}$ of $2.5^{\circ} \mathrm{C}$ over the Atlantic area $20^{\circ}-30^{\circ} \mathrm{N}, 40^{\circ} \mathrm{W}-0^{\circ}$, together with a reduction in MSLP of $2 \mathrm{hPa}$ in the same area. Cloud is increased both in this region and also farther south and east over the precipitation band of the WAM, which is itself increased in the active dust case. The OLR is reduced over almost the entire region because of the increased cloud and presence of dust. A notable exception to this is the area west of the $30^{\circ} \mathrm{W}$ and between $0^{\circ}$ and $10^{\circ} \mathrm{N}$, which covers the Guinea Highlands region of South America and the neighboring tropical Atlantic Ocean. Here the cloud and precipitation are reduced and the OLR increased in ActD2. This will be analyzed further after considering the climatology of North Africa.

Figure 13 compares the 18-yr August monthly mean zonal wind over West Africa $\left(20^{\circ} \mathrm{W}-10^{\circ} \mathrm{E}\right)$ for PasD2 and ActD2. From the vertical cross sections (top panel) the AEJ can be seen at approximately $600 \mathrm{hPa}$ and the TEJ can be seen at approximately $200 \mathrm{hPa}$. At the surface the westerly component of the monsoon flow can be 


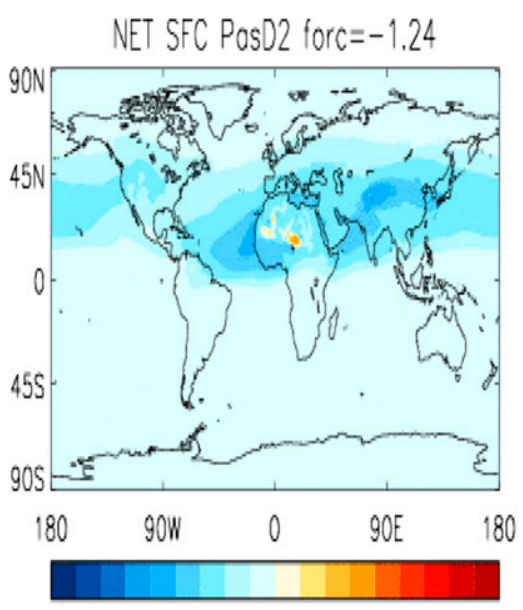

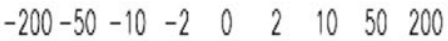
SW SFC PoSD2 forc $=-1.71$

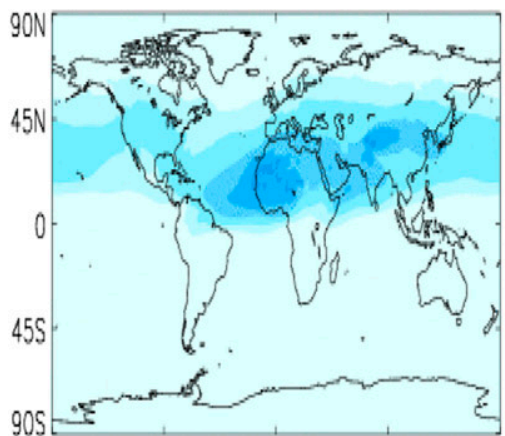

180 gOW O GOE $\quad 180$

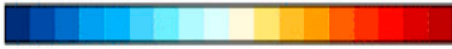

$-200-50-10-2 \quad 0 \quad 2 \quad 10 \quad 50 \quad 200$

LW SFC POSD2 forc $=0.48$

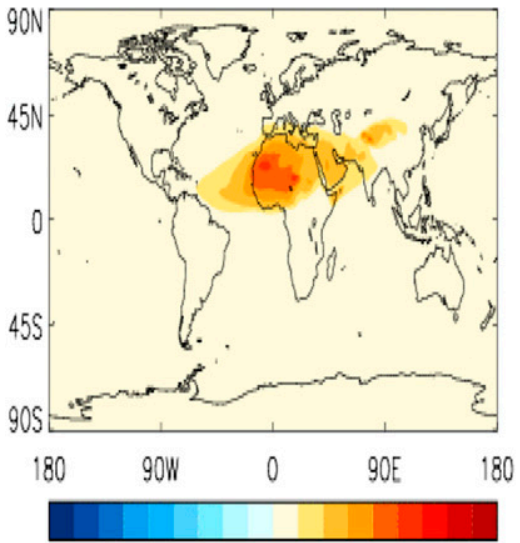

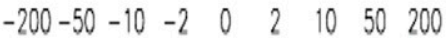

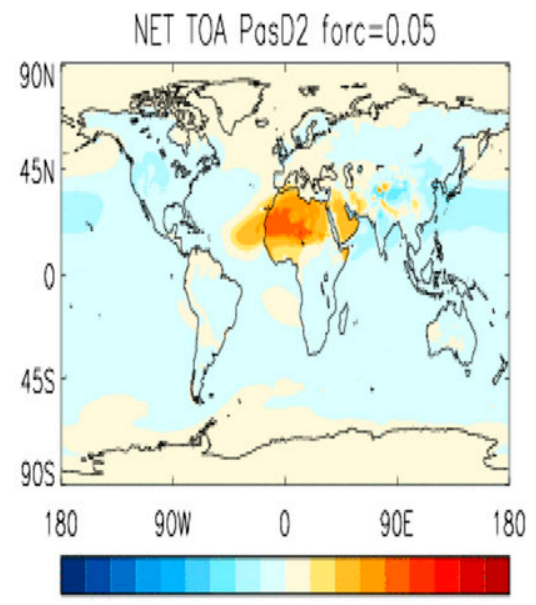

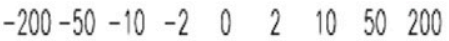
SW TOA PosD2 forc $=-0.27$
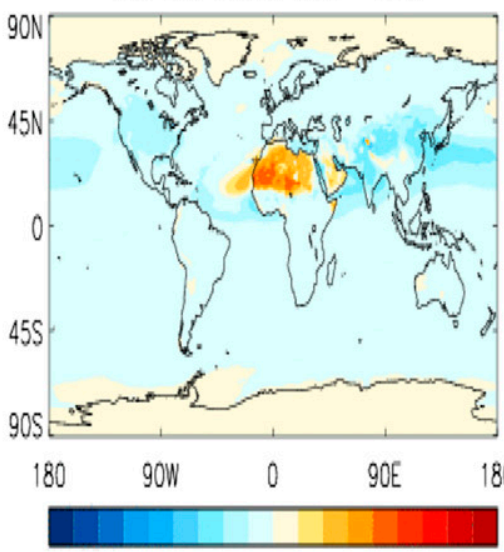

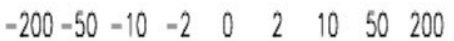

LW TOA POSD2 forc $=0.32$

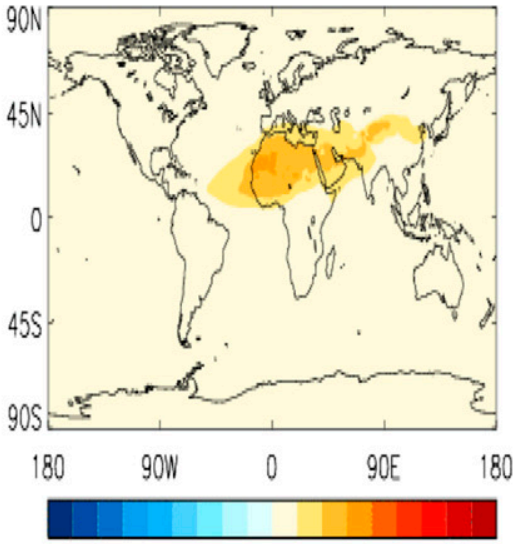

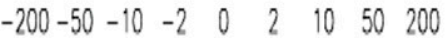

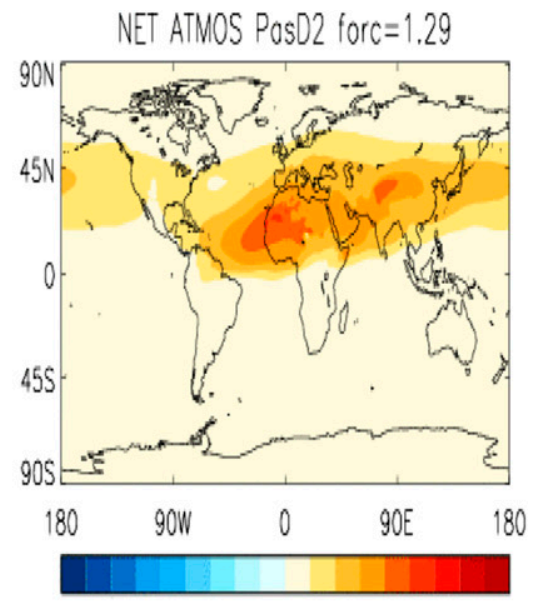

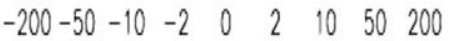
SW TOA-SFC POSD2 forc $=1.45$

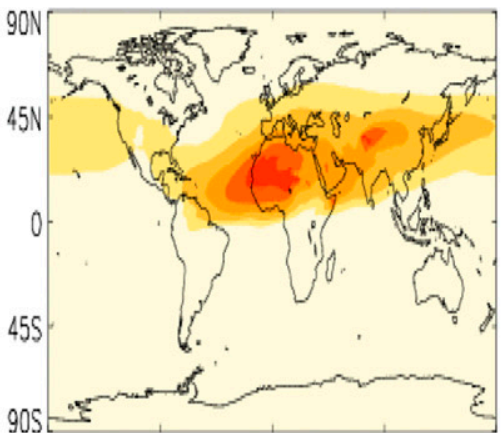

180 90W O 90E 180

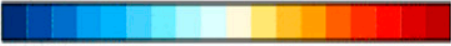

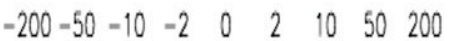

LW TOA-SFC POSD2 forc $=-0.16$
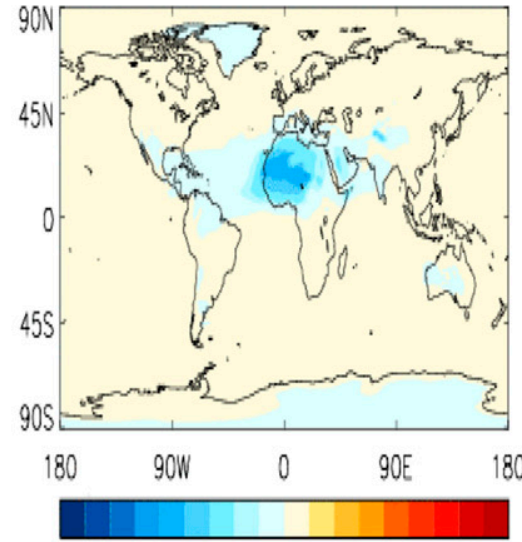

$-200-50-10 \quad-2 \quad 0 \quad 2 \quad 10 \quad 50 \quad 200$

FIG. 10. The 18-yr annual mean dust radiative forcing $\left(\mathrm{W} \mathrm{m}^{-2}\right)$ from experiment PasD2 (left) at the SFC, (center) at the TOA, and (right) in the atmosphere. Shown are (top) net values (SW + LW), (middle) shortwave, and (bottom) longwave components. 


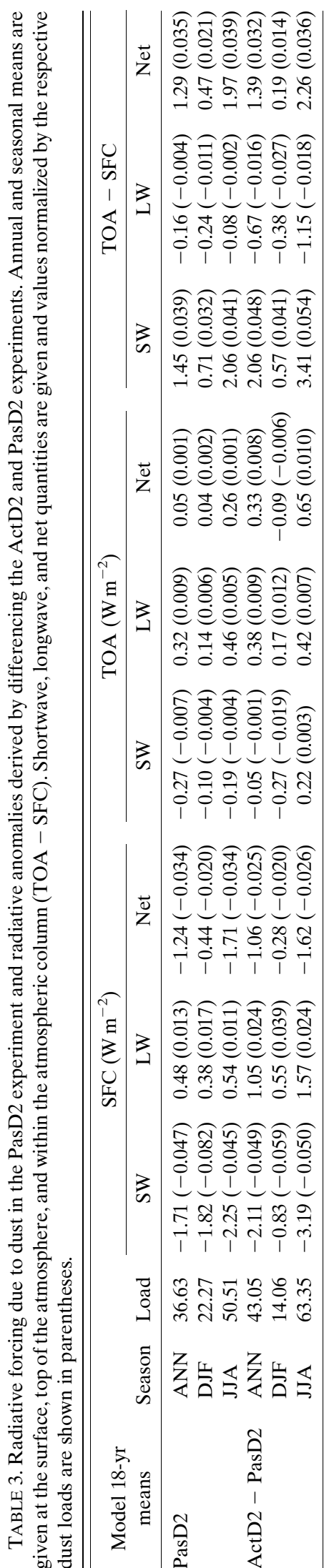

seen underlying the AEJ; this is slightly stronger in the active dust experiment, forcing the AEJ slightly higher in the vertical and farther north in latitude. The core of the AEJ is about $3^{\circ}$ farther north and $0.5 \mathrm{~m} \mathrm{~s}^{-1}$ stronger in ActD2, as can be seen more clearly in the bottom panel of the $600-\mathrm{hPa}$ zonal wind for the two experiments. The tropical easterly jet $(\sim 200 \mathrm{hPa})$ is also strengthened in ActD2. The differences are similar to the wet year composite shown in Fig. 6 of Nicholson (2009), which compares the jet structures in wet and dry monsoon years; there it is argued that, in addition to the southerly monsoon flow, a low-level westerly jet arises in wet years controlled by the surface pressure gradient over the tropical Atlantic. Examining the corresponding change in the monsoon precipitation in HiGAM, Fig. 14 (top) shows that the region of maximum precipitation is shifted about $2^{\circ}$ farther north in ActD2 and the meridionally averaged rate is increased by $1.5 \mathrm{~mm} \mathrm{day}^{-1}$. A northward shift of the ITCZ with enhanced precipitation on its north side in association with Saharan dust outbreaks is also reported by Wilcox et al. (2010) in their analysis of satellite observations. The bottom panel in Fig. 14 shows the monthly mean precipitation rate throughout the year over the WAM region for the two dust experiments and for the Climate Prediction Center (CPC) Merged Analysis of Precipitation (CMAP) climatology (Xie and Arkin 1997). From November to March there is little difference between the active and passive dust experiments and they match the CMAP data quite well. However, from April to October ActD2 has up to $50 \%$ more precipitation than PasD2, and neither captures the seasonality of the CMAP data very well, peaking too early in the year. However, the peak is sustained throughout the summer and in August (the month with maximum precipitation) the models lie either side of the CMAP data, with ActD2 matching the CMAP data slightly better than PasD2. Root-mean-square (rms) error analysis shows that PasD2 matches CMAP data better than ActD2 for the first half year (January-June; rms errors 0.31 and $0.97 \mathrm{~mm}_{\text {day }}{ }^{-1}$, respectively), while ActD2 is closer to CMAP values for the July-December period (rms errors of $0.57 \mathrm{~mm} \mathrm{day}^{-1}$ for ActD2 and $0.66 \mathrm{~mm} \mathrm{day}^{-1}$ for PasD2).

Figure 15 shows the differences between the vertical cross sections of the dust concentrations and temperature profiles for ActD2 and PasD2 over north Africa (NA), where larger, more absorbent particles dominate, and over IN-CH, where smaller, more scattering particles dominate (see Fig. 7). In both areas the dust creates an elevated heat source northward of the region of highest dust concentration, but over IN-CH this is isolated from the surface, whereas over NA the heating is stronger and extends to the surface. In NA there is cooling at the 
NET SFC D2 anom $=-1.06$

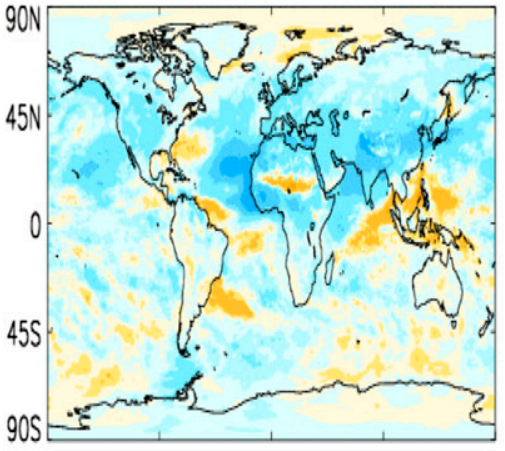

180 gOW $\quad 0 \quad$ gOE $\quad 180$

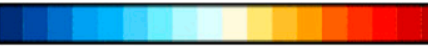

$-200-50-10-2 \quad 0 \quad 2 \quad 10 \quad 50 \quad 200$ SW SFC D2 onom $=-2.11$

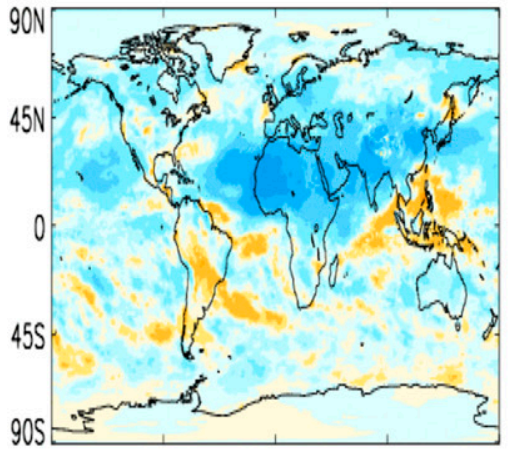

180 GOW O GOE 180

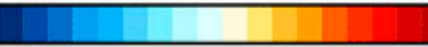

$-200-50-10-2 \quad 0 \quad 2 \quad 10 \quad 50 \quad 200$ LW SFC D2 onom $=1.05$

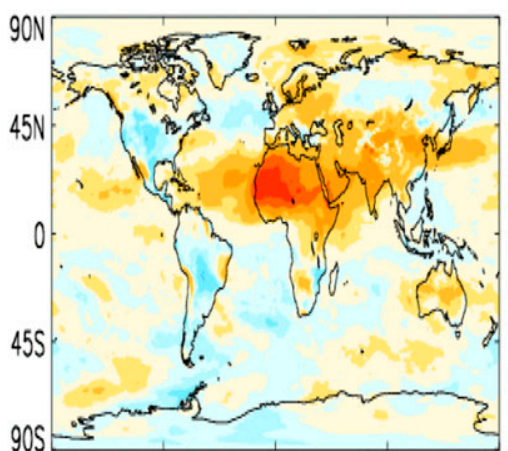

180 GOW O GOE $\quad 180$

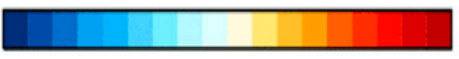

$-200-50-10-2 \quad 0 \quad 2 \quad 10 \quad 50 \quad 200$
NET TOA D2 onom $=0.33$

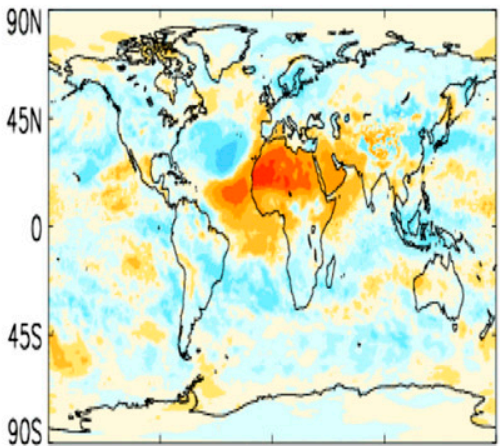

180 gOW O GOE 180

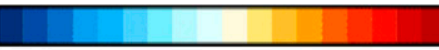

$-200-50-10-2 \quad 0 \quad 2 \quad 10 \quad 50200$ SW TOA D2 anom $=-0.05$

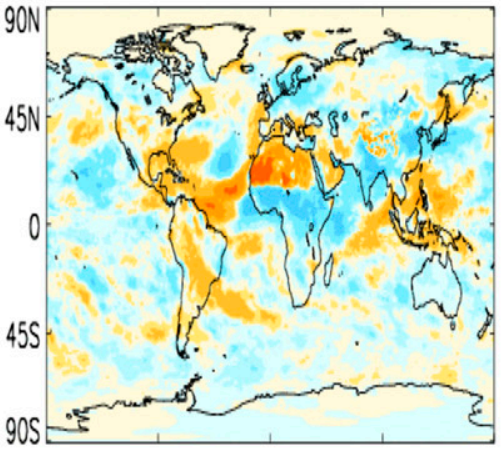

180 gOW O gOE 180

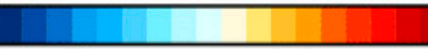

$-200-50-10-2 \quad 0 \quad 2 \quad 10 \quad 50200$ LW TOA D2 onom $=0.38$

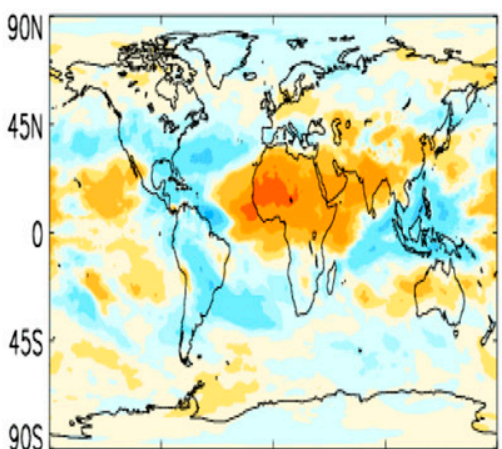

180 9OW $\quad 0 \quad 90 E \quad 180$

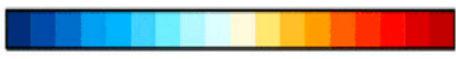

$-200-50-10-2 \quad 0 \quad 2 \quad 10 \quad 50 \quad 200$
NET ATMOS D2 onom $=1.39$

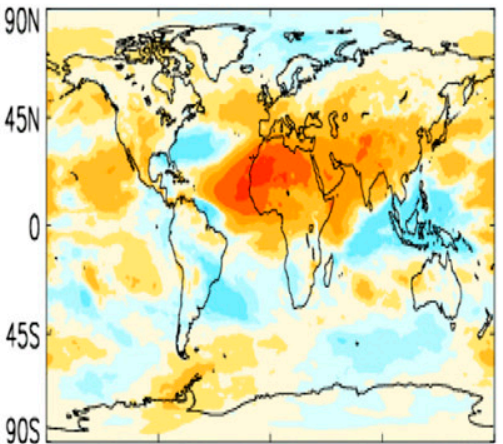

180 gOW O 9OE 180

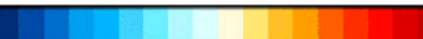

$-200-50-10-2 \quad 0 \quad 2 \quad 10 \quad 50200$ SW TOA-SFC D2 onom $=2.06$

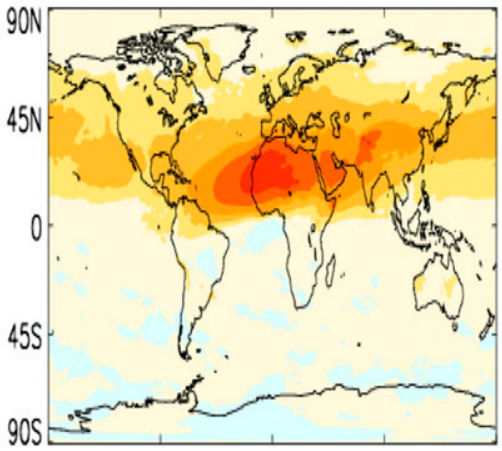

180 gOW O gOE 180

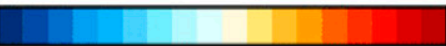

$-200-50-10-2 \quad 0 \quad 2 \quad 10 \quad 50200$ LW TOA-SFC D2 onom $=-0.67$
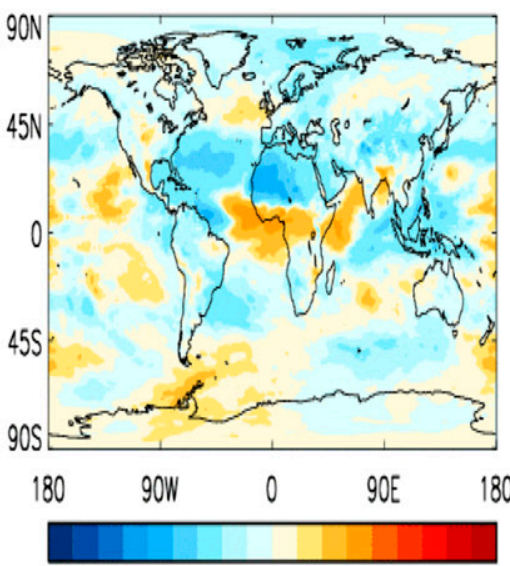

$-200-50-10-2 \quad 0 \quad 2 \quad 10 \quad 50200$

FIG. 11. As in Fig. 10, but for dust radiative anomaly $\left(\mathrm{W} \mathrm{m}^{-2}\right)$ from experiments (ActD2 - PasD2). 
TABLE 4. Global annual mean precipitation $\left(\mathrm{mm} \mathrm{day}^{-1}\right)$, cloud fraction, and cloud forcing for the passive and active dust experiments. Cloud forcing column headings as in Table 3.

\begin{tabular}{|c|c|c|c|c|c|c|c|c|c|c|c|}
\hline \multirow[b]{3}{*}{ Model 18-yr means } & \multirow{3}{*}{$\begin{array}{l}\text { Global } \\
\text { PPTN }\end{array}$} & \multirow{3}{*}{$\begin{array}{c}\text { Global } \\
\text { CLOUD }\end{array}$} & \multicolumn{9}{|c|}{ Global cloud forcing $\left(\mathrm{W} \mathrm{m}^{-2}\right)$} \\
\hline & & & \multicolumn{3}{|c|}{ SFC } & \multicolumn{3}{|c|}{ TOA } & \multicolumn{3}{|c|}{ TOA - SFC } \\
\hline & & & SW & LW & Net & SW & LW & Net & SW & LW & Net \\
\hline PasD2 & 3.10 & 0.52 & -46.3 & 21.7 & -24.6 & -43.6 & 25.7 & -17.9 & 2.7 & 4.0 & 6.7 \\
\hline ActD2 & 3.07 & 0.52 & -45.7 & 21.5 & -24.2 & -42.9 & 25.2 & -17.7 & 2.8 & 3.7 & 6.5 \\
\hline
\end{tabular}

surface southward of the region of highest dust concentration, but in IN-CH there is cooling or no change in the whole surface layer to a depth of $2 \mathrm{~km}$. Therefore we see that over NA the dust has created the potential for increased convective overturning, which will stimulate further dust emission from the surface and loft it higher in the atmosphere. On the other hand, over IN-CH, the atmospheric column is stabilized by the dust, thus reducing the potential for convection and dust emission from the surface (see Fig. 6 and comments in section 2).

The bottom panel in Fig. 15 shows a cross section through the area covering the Guinea Highlands region of South America and the neighboring tropical Atlantic Ocean (GUIH). Here there are no dust emissions but the dust plume emanating from the Sahara can be seen centered around $600-700 \mathrm{hPa}(\sim 4 \mathrm{~km})$. Note that the dust concentrations above this level are very similar to those in the plume over North Africa (see top-left panel), although below this level they are much reduced because of deposition of the larger particles. There is gentle warming throughout the column south of $10^{\circ} \mathrm{N}$, and from Fig. 12 we see that there is a slight increase in MSLP, dissipation of cloud, and a reduction in precipitation. Table 5 compares the precipitation for ActD2 and PasD2 for ANN and JJA for the whole globe, for northwest Africa, and for the GUIH region. As noted above, the global annual mean precipitation change is small $(-1 \%)$ in ActD2, but in JJA this reduction is greater and over GUIH the JJA reduction is more than double the ANN value at $-20 \%$. The WAM precipitation, however, shows the largest change with an increase of $23 \%$ annually and $40 \%$ in JJA when dust feedbacks are included.

\section{Discussion}

\section{a. Dust loadings, emissions, and particle size distributions}

In contrast to our results with HiGAM, other models have shown a reduction in global dust loads when radiative feedbacks are included. For example, Perlwitz et al. (2001) experimented with varying spectral properties of the dust aerosol in a global climate model and found reductions in global burdens varied from $18 \%$ for more scattering aerosol to $17 \%$ for more absorbent aerosol; however, their largest dust particles were $8 \mu \mathrm{m}$ (smaller than in HiGAM). Using the same basic model, Miller et al. (2004a) investigated the reasons for the negative feedback on dust emission, which in their version varied from $16 \%$ to $19 \%$ for the different spectral properties. Their explanation for the reduction was that the surface is cooled and the atmosphere stabilized, thereby reducing turbulence and dust emissions. However, they note at the end of their paper that larger particles $(>10 \mu \mathrm{m})$, though having a short lifetime and therefore small impact on the global radiation budget, could have a significant warming effect near the surface because of their longwave absorption. This offsets the nocturnal surface cooling and maintains the mixing and surface winds in the boundary layer after sunset. They argue that with sufficient large particles the net surface forcing would become positive, leading to positive feedback on dust emissions. Pérez et al. (2006) reported a strong negative feedback on dust emissions using a limited area North African-Mediterranean regional model to investigate a dust-plume case study. They found $35 \%-$ $45 \%$ reduction in aerosol optical depth (AOD) in the dust plume but provided no data on burdens to indicate whether or not the dust size distribution had been affected (which would change the AOD). Their model only included particles $<10 \mu \mathrm{m}$ but did include longwave effects.

Clearly, the balance between the warming and cooling effects of the dust is crucial. If SW cooling effects at the surface dominate then the feedback on dust production will be negative; conversely, if LW warming effects dominate then the feedback will be positive. Some models do not include the full range of particle sizes, and some neglect LW effects completely because they are deemed to be globally smaller than the SW effects. However, as shown here and as pointed out by Miller et al. (2004a), they can have an important effect in controlling the emissions at source. Interestingly, some of the earlier papers on the impacts of dust emphasized the importance of the LW effect (e.g., Claquin et al. 1998), but this has been neglected in some of the more recent work. Lau et al. (2009) do include LW effects in their GCM study of the response of the West African water cycle to Saharan dust forcing. They find that the elevated heat pump (EHP) effect dominates over West Africa and the east Atlantic, 

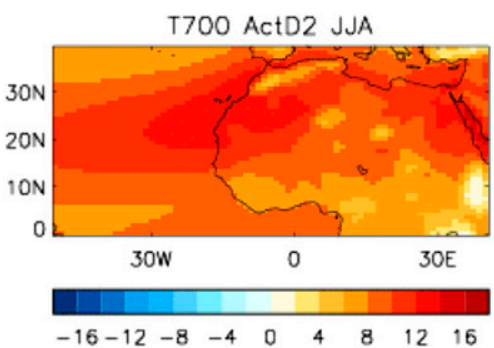

OLR ActD2 JJA
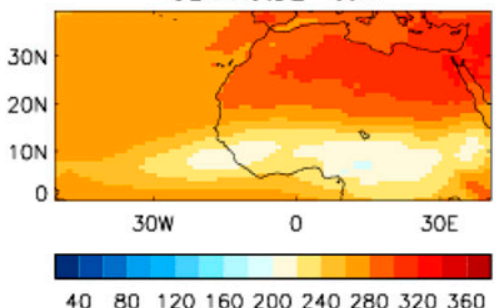

CLOUD ActD2 JJA

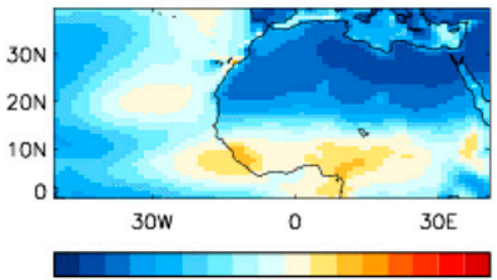

$\begin{array}{lllllllll}0 & 0.15 & 0.3 & 0.45 & 0.6 & 0.75 & 0.9 & 1.05\end{array}$ MSLP ActD2 JJA

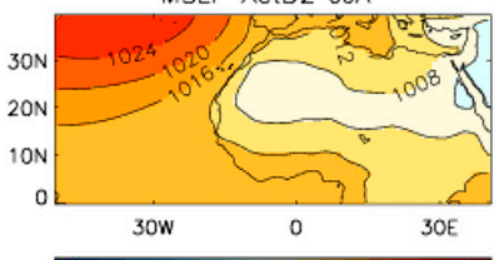

97298098899610041012102010281036

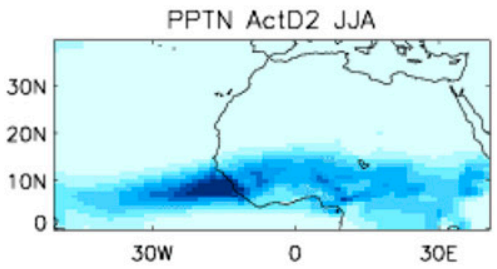

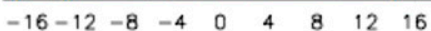
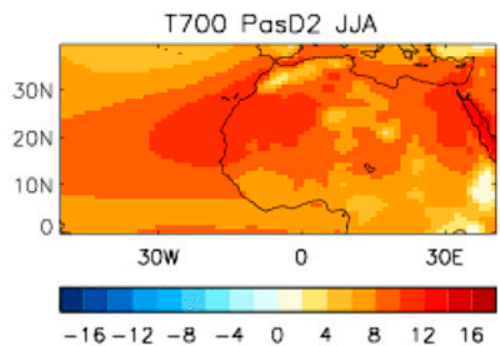

OLR PasD2 JJA

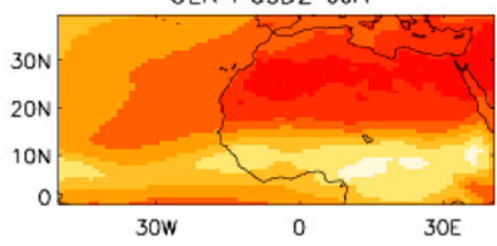

$40 \quad 80 \quad 120 \quad 160200240280320360$ CLOUD PasD2 JJA

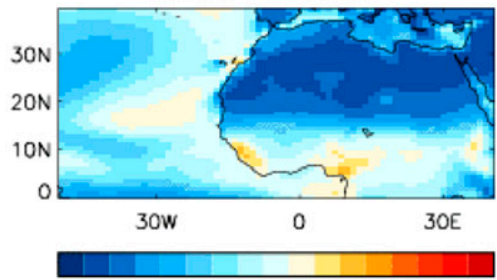

$\begin{array}{llllllll}0 & 0.15 & 0.3 & 0.45 & 0.6 & 0.75 & 0.9 & 1.05\end{array}$ MSLP POSD2 JJA

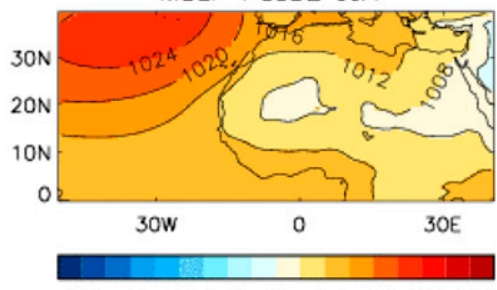

97298098899610041012102010281036

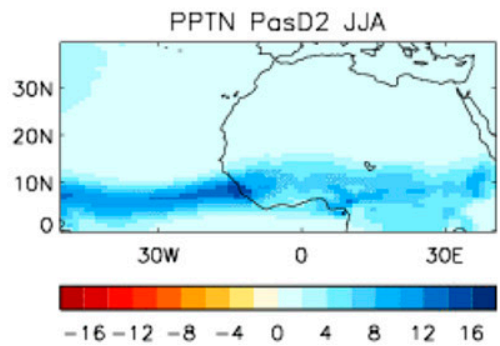

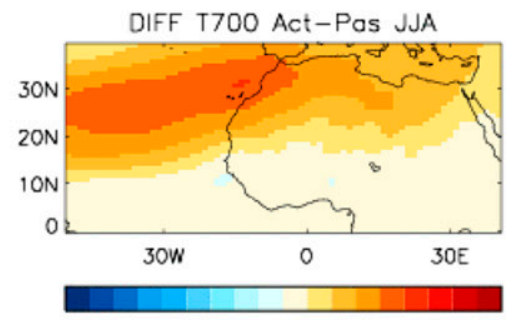

$\begin{array}{lllllllll}-4 & -3 & -2 & -1 & 0 & 1 & 2 & 3 & 4\end{array}$

DIFF OLR Act-Pas JJA
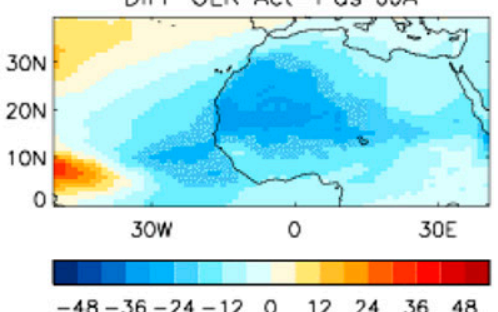

DIFF CLOUD Act-Pas JJA

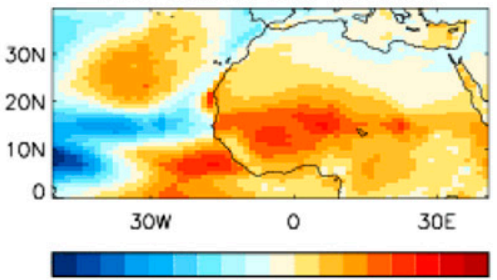

$-0.240 .180 .1 z 0.0600 .060 .120 .180 .24$ DIFF MSLP Act-Pas JJA

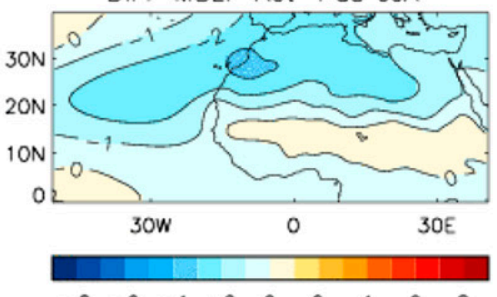

$\begin{array}{lllllllll}-8 & -6 & -4 & -2 & 0 & 2 & 4 & 6 & 8\end{array}$

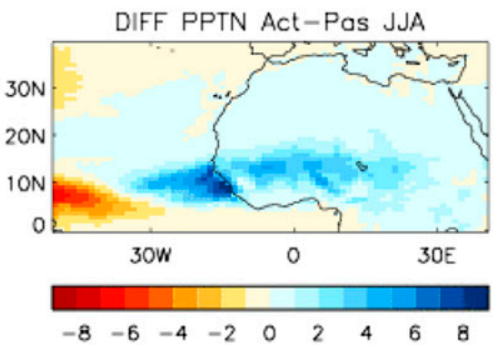

FIG. 12. (top)-(bottom) The 18 -yr JJA means of 700-hPa temperature $\left({ }^{\circ} \mathrm{C}\right)$, outgoing $\mathrm{LW}$ radiation $\left(\mathrm{W} \mathrm{m}^{-2}\right)$, cloud fraction, mean sea level pressure $(\mathrm{hPa})$, and precipitation rate $\left(\mathrm{mm} \mathrm{day}^{-1}\right)$ for (left) ActD2, (center) PasD2, and (right) their differences.

enhancing the WAM precipitation in the same way as in HiGAM. However, they do not investigate possible feedbacks on the dust production itself.

\section{b. Dust radiative forcing and radiative anomalies}

The impact of switching on the dust radiative effects is to make the radiative anomalies in ActD2 at both SFC and TOA more positive than the corresponding forcings in PasD2 (except in DJF at TOA, where the values are anyway close to zero). This is achieved by reducing the proportion of smaller particles, which have negative forcing at both SFC and TOA. The annual mean global TOA anomaly is $0.33 \mathrm{~W} \mathrm{~m}^{-2}$ (rather than $0.05 \mathrm{~W} \mathrm{~m}^{-2}$ in PasD2), although this rises to $0.65 \mathrm{~W} \mathrm{~m}^{-2}$ in $\mathrm{JJA}$ and 

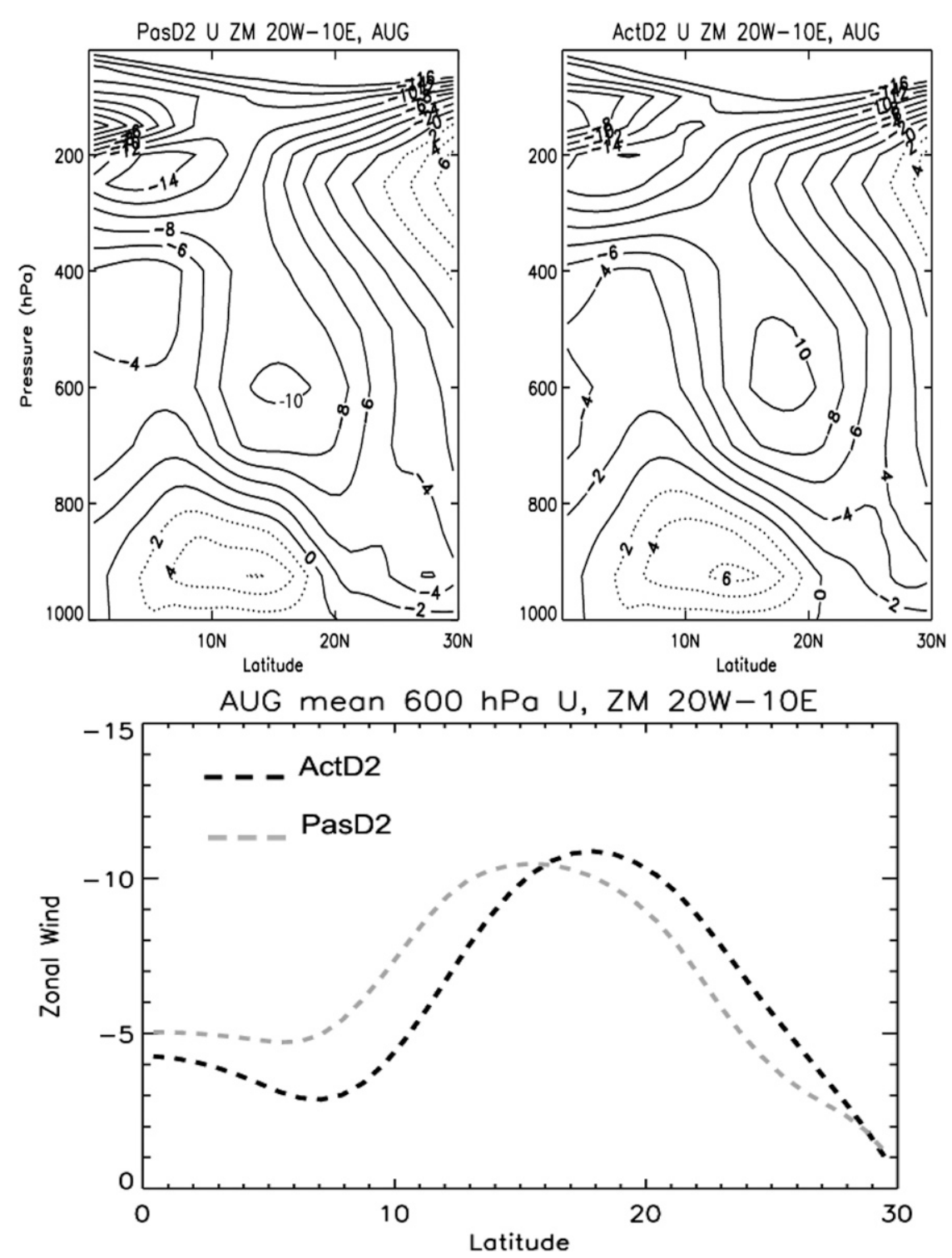

FIG. 13. The August zonal mean zonal wind $\left(\mathrm{m} \mathrm{s}^{-1}\right.$; westerly positive) over the region $20^{\circ} \mathrm{W}-$ $10^{\circ} \mathrm{E}, 0^{\circ}-30^{\circ} \mathrm{N}$. (top) Vertical cross sections for the (left) passive and (right) active dust experiments. (bottom) The zonal wind at $600 \mathrm{hPa}$ for the two experiments.

becomes negative $\left(-0.09 \mathrm{~W} \mathrm{~m}^{-2}\right)$ in DJF. The corresponding forcings in PasD2 are smaller in magnitude, $0.26 \mathrm{~W} \mathrm{~m}^{-2}$ in JJA and positive $\left(0.04 \mathrm{~W} \mathrm{~m}^{-2}\right)$ in DJF. This is important, as the anomalies show what might be the true impact of dust on the atmosphere, rather than the forcing which is often used as a measure of the impact but does not include feedback effects. We have acknowledged that the dust loadings in our experiments are high compared with some other results, so it might be argued that the radiative anomalies and forcings will also be proportionally high. However, even if our burdens were halved, we would still expect an annual mean TOA radiative anomaly of $0.16 \mathrm{~W} \mathrm{~m}^{-2}$ compared with an equivalent forcing of $0.02 \mathrm{~W} \mathrm{~m}^{-2}$, which is a significant increase. The radiative properties of dust used in HiGAM are spatially uniform and derived from various sources representing dust from different locations to make them globally representative (see section 2). Therefore, although perhaps less good than those used by some regional models for the Sahara, they are more realistic than many other models for other areas of the globe, which is clearly important for climate impact studies investigating radiative effects.

\section{c. Impact of dust forcing on regional climatologies}

Other modeling work, such as that of Pérez et al. (2006), Yoshioka et al. (2007), Solmon et al. (2008), and 

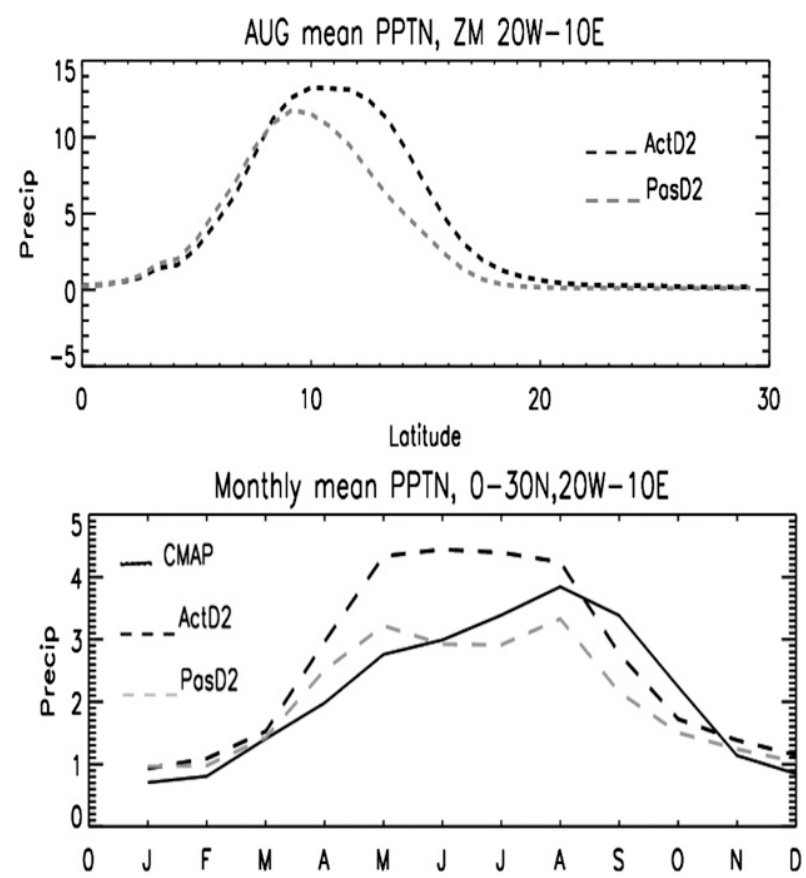

FIG. 14. (top) Zonally averaged precipitation rate $\left(\mathrm{mm} \mathrm{day}^{-1}\right)$ for August for each latitude band $20^{\circ} \mathrm{W}-10^{\circ} \mathrm{E}$ for ActD2 and PasD2, and (bottom) 18-yr averaged monthly precipitation rate $\left(\mathrm{mm} \mathrm{day}^{-1}\right)$ through the year from January to December for the region $0^{\circ}-30^{\circ} \mathrm{N}, 20^{\circ} \mathrm{W}-10^{\circ} \mathrm{E}$ for $\mathrm{ActD} 2, \mathrm{PasD} 2$, and $\mathrm{CMAP}$ rainfall data (see text).

Konare et al. (2008) has shown that dust aerosol acts to decrease the WAM rainfall, in contrast to our result showing increased precipitation. However, Konare et al. (2008) consider shortwave affects only and conclude that LW effects, though less important than SW effects, should be taken into consideration. Yoshioka et al. (2007) also report that the LW forcing of dust acts to increase the Sahelian precipitation significantly and that it considerably offsets the very large effect of SW forcing in reducing precipitation. Solmon et al. (2008) find two competing effects: a surface cooling, which acts to reduce monsoon precipitation, and an EHP (Lau et al. 2006; Lau and Kim 2006; Lau et al. 2010), which acts to increase it. In this, the aerosol acts to warm the upper troposphere, thereby increasing cloudiness, deep convection, and rainfall. Conversely, if the reflecting properties of the aerosol dominate, then it has a cooling, stabilizing effect (Miller et al. 2004a) in which convection and rainfall are inhibited. We find the same mechanisms operating here, with precipitation reduced over the GUIH region; however, because the dust in our model is more absorbent than that used by Solmon et al. (2008), the EHP effect dominates over North Africa in HiGAM. Teleconnections between the precipitation across the tropical Atlantic may be a contributory factor and have been noted in other work; for example, Rodwell and Jung (2008) found an increase in the west and a decrease in the east when new aerosol climatology (with reduced Saharan dust) was introduced into the ECMWF model.

We note that our results are in agreement with recent modeling work using more absorbent dust such as that of Solmon et al. (2012), who find an increase in summertime precipitation in the northern Sahel when dust radiative effects are included; also Perlwitz and Miller (2010) report increases in cloud and precipitation in regions where dust induces a positive TOA radiative forcing.

\section{Conclusions}

We have considered the impact of including the direct radiative effect of mineral dust aerosol in a highresolution atmospheric model (HiGAM). We have shown that both the EHP and the turbulence damping effects are active in our model; the former dominates where larger particles are the majority and the latter dominates where smaller particles are in excess. The global annual mean dust burden is increased when radiative effects are included and the WAM precipitation is also increased. While this contrasts with some other modeling results, we have explained that this is because our dust model includes larger particle sizes; has more absorbent and globally representative spectral properties; and includes LW effects, which have been neglected in many other studies. It may be argued that this exaggerates the EHP effect over the Sahara, but recent data from the Fennec project (Ryder et al. 2013) and measurements from the Saharan Mineral Dust Experiment (SAMUM; e.g., Weinzierl et al. 2011) show evidence of larger dust size modes (up to $40-\mu \mathrm{m}$ diameter) over the Sahara. Although they are short lived, they can impact the temperature profile, stability, and dust emissions and should not be neglected. The impact of the dust on the AEJ and WAM precipitation in August matches that observed in wet years relative to dry years in the region (Nicholson 2009). A northward shift in the ITCZ has also been observed in association with dust outbreaks (Wilcox et al. 2010). The impact of switching on the dust radiative effects is to make the annual mean radiative anomalies at both SFC and TOA more positive than the corresponding forcings. This is achieved because of a reduction in the proportion of smaller particles, which have negative forcing at both SFC and TOA. Whereas the global annual mean TOA forcing is close to zero, the corresponding radiative anomaly shows a significant warming $\left(0.33 \mathrm{~W} \mathrm{~m}^{-2}\right)$. 


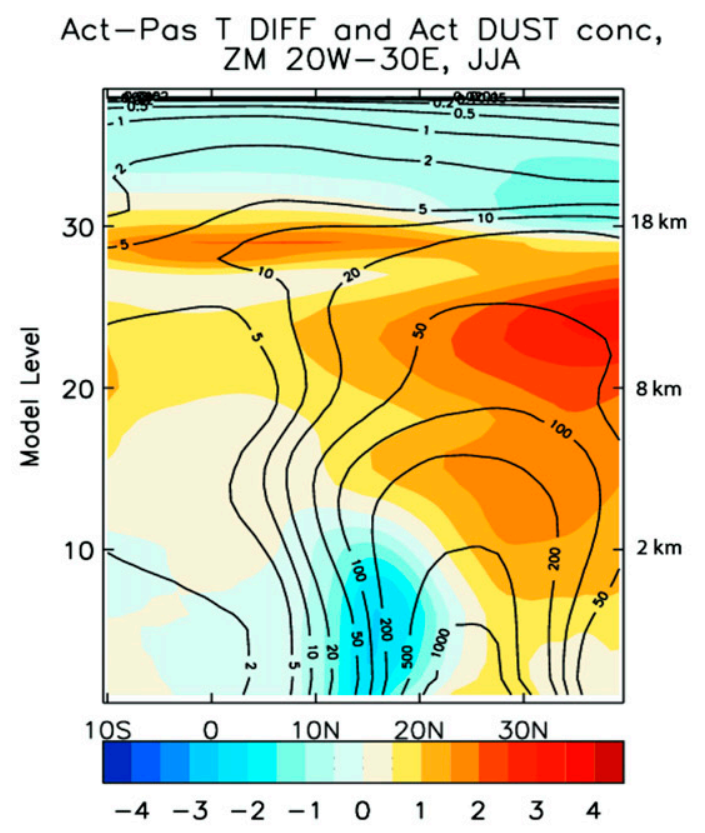

Act-Pas T DIFF and Act DUST conc, ZM 70W-30W, JJA

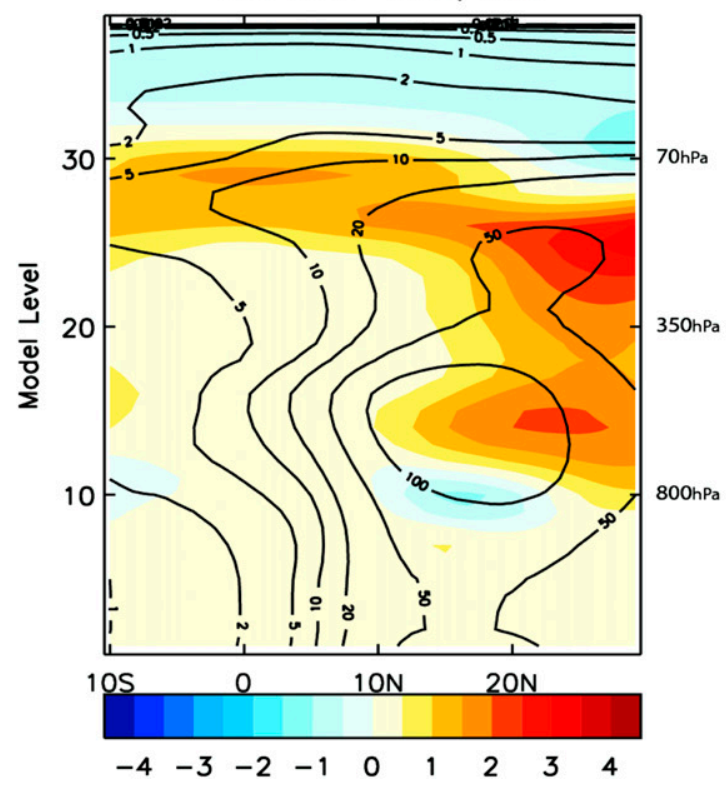

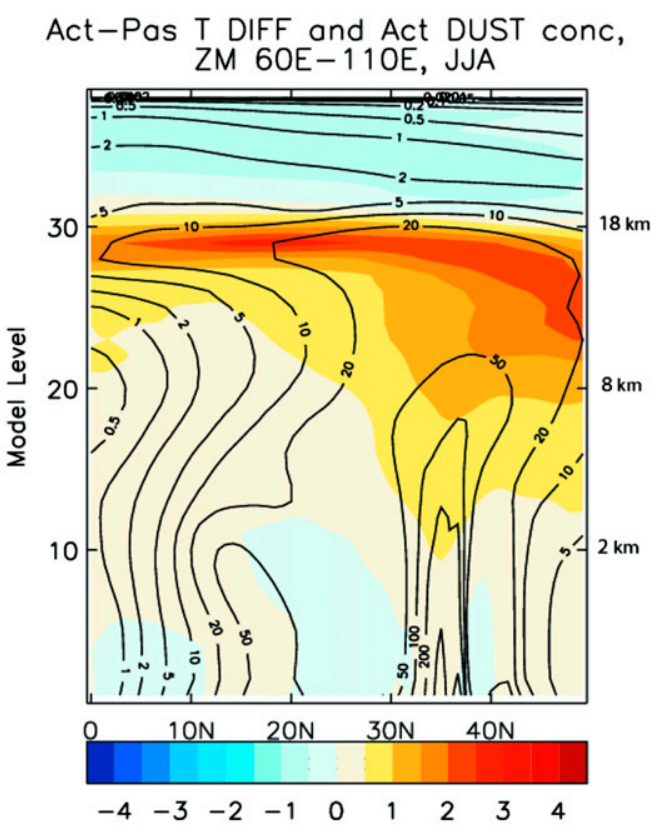

FIG. 15. The 18-yr mean JJA vertical cross sections of ActD2 - PasD2 temperature differences $\left({ }^{\circ} \mathrm{C}\right.$; colored filled contours) and ActD2 dust concentrations ( $\mu \mathrm{g} \mathrm{kg}^{-1}$; open black contours) for (top left) a section zonally meaned through Africa $\left(20^{\circ} \mathrm{W}-\right.$ $30^{\circ} \mathrm{E}$ ); (top right) a section zonally meaned through India and China $\left(60^{\circ}-110^{\circ} \mathrm{E}\right)$; and (bottom left) a section zonally meaned through the western Atlantic region $\left(70^{\circ}-30^{\circ} \mathrm{W}\right)$.
We believe that these results extend the existing range of modeling work and possible dust impact scenarios. They emphasize the need for further observational studies to allow more realistic dust particle sizes and spectral properties to be included in models to determine the true dust aerosol impacts both regionally and globally. The dust particle size distributions in HiGAM have been crucial to our results; they are determined by the soil texture, soil moisture, surface winds, and deposition processes, which vary on a range of scales within and between regions. An in-depth analysis of all these differences was beyond the scope of this study, but experiments with a different parent soil texture file have been carried out and indicate that this is an important factor (results to be submitted in a future publication). Supporting evidence for regional differences in emitted dust particle sizes can be in found in Fig. 9 of Huneeus et al. (2012), which indicates that a higher ratio of coarse to fine particles are emitted from the Sahara relative to Asia. 
TABLE 5. Precipitation rates for experiments ActD2 and PasD2 and their differences over the whole globe (GLOB), northwest Africa, and the Guinea Highlands region of South America $\left(70^{\circ} \mathrm{W}-30^{\circ} \mathrm{W}, 10^{\circ} \mathrm{S}-30^{\circ} \mathrm{N}\right)$.

\begin{tabular}{lllcc}
\hline \hline \multirow{2}{*}{ Expt } & & \multicolumn{3}{c}{ Mean PPTN $\left(\mathrm{mm}_{\text {day }}{ }^{-1}\right)$} \\
\cline { 3 - 5 } & Season & GLOB & NWAF & GUIH \\
\hline ActD2 & ANN & 3.07 & 2.14 & 3.82 \\
& JJA & 3.12 & 3.36 & 3.13 \\
PasD2 & ANN & 3.10 & 1.74 & 4.22 \\
& JJA & 3.18 & 2.40 & 3.94 \\
ActD2 - PasD2 & ANN & $-0.03(-1.0 \%)$ & $+0.40(+23.0 \%)$ & $-0.40(-9.5 \%)$ \\
& JJA & $-0.06(-1.9 \%)$ & $+0.96(+40.0 \%)$ & $-0.81(-20.0 \%)$ \\
\hline
\end{tabular}

We have used an atmosphere-only model with imposed SSTs in order to focus the available computer resources on running for as many model years as possible with a fully interactive dust scheme. The presence of dust over sea areas has the potential to reduce the SSTs and surface evaporation (e.g., Miller and Tegen 1998; Yue et al. 2011); in particular, Saharan dust over the Atlantic Ocean could influence dust production over North Africa. However, in our experiments, the yearon-year dust loadings do not show significant correlation with the North Atlantic SSTs, so it is not clear that including this effect would substantially change our results. A sensitivity study with reduced SSTs in different areas, similar to the study of Solmon et al. (2012), would be an interesting area for future study.

Acknowledgments. The financial support of the Natural Environment Research Council through the U.K. HiGEM project and the National Centre for Earth Observation (H5043118) is gratefully acknowledged. This work made use of the High End Computing Terascale Resources at Edinburgh, funded by the U.K. Research Councils. The work of Stephanie Woodward was supported by the Joint DECC/Defra Met Office Hadley Centre Climate Programme (GA01101). We also thank Ron L. Miller, Jasper Kok, and an anonymous reviewer for their helpful suggestions, which have improved this manuscript.

\section{REFERENCES}

Allan, R. P., M. J. Woodage, S. F. Milton, M. E. Brooks, and J. M. Haywood, 2011: Examination of long-wave radiative bias in general circulation models over North Africa during MayJuly. Quart. J. Roy. Meteor. Soc., 137, 1179-1192, doi:10.1002/ qj.717.

Bagnold, R. A., 1941: The Physics of Blown Sand and Desert Dunes. Methuen, $265 \mathrm{pp}$.

Balkanski, Y., M. Schulz, T. Claquin, and S. Guibert, 2007: Reevaluation of mineral aerosol radiative forcings suggests a better agreement with satellite and AERONET data. Atmos. Chem. Phys., 7, 81-95, doi:10.5194/acp-7-81-2007.
Carlson, T. N., and S. G. Benjamin, 1980: Radiative heating rates for Saharan dust. J. Atmos. Sci., 37, 193-213, doi:10.1175/ 1520-0469(1980)037<0193:RHRFSD>2.0.CO;2.

Claquin, T., M. Schulz, Y. Balkanski, and O. Boucher, 1998: Uncertainties in assessing radiative forcing by mineral dust. Tellus, 50B, 491-505, doi:10.1034/j.1600-0889.1998.t01-2-00007.x.

Cook, K. H., 1999: Generation of the African easterly jet and its role in determining West African precipitation. J. Climate, 12,1165-1184, doi:10.1175/1520-0442(1999)012<1165: GOTAEJ $>2.0 . \mathrm{CO} ; 2$.

Deepak, A., and H. E. Gerber, Eds., 1983. Report of the experts meeting on aerosols and their climatic effects. WMO Rep. WCP-55, 107 pp.

Duce, R. A., 1995: Sources, distributions and fluxes of mineral aerosols and their relationship to climate. Aerosol Forcing of Climate: Report of the Dahlem Workshop on Aerosol Forcing of Climate, R. J. Charlson and J. Heintzenberg, Eds., John Wiley \& Sons, 43-72.

Edwards, J. M., and A. Slingo, 1996: Studies with a flexible new radiation code. I: Choosing a configuration for a large-scale model. Quart. J. Roy. Meteor. Soc., 122, 689-719, doi:10.1002/ qj. 49712253107.

Forster, P., and Coauthors, 2007: Changes in atmospheric constituents and in radiative forcing. Climate Change 2007: The Physical Science Basis, S. Solomon et al., Eds., Cambridge University Press, 129-234.

Gillette, D. A., 1979: Environmental factors affecting dust emission by wind erosion. Saharan Dust: Mobilization, Transport, Deposition, C. Morales, Ed., John Wiley \& Sons, 71-91.

Harries, J. E., and Coauthors, 2005: The Geostationary Earth Radiation Budget project. Bull. Amer. Meteor. Soc., 86, 945960, doi:10.1175/BAMS-86-7-945.

Haywood, J. M., R. P. Allan, I. Culverwell, T. Slingo, S. Milton, J. M. Edwards, and N. Clerbaux, 2005: Can desert dust explain the outgoing longwave radiation anomaly over the Sahara during July 2003? J. Geophys. Res., 110, D05105, doi:10.1029/ 2004JD005232.

Huneeus, N., F. Chevallier, and O. Boucher, 2012: Estimating aerosol emissions by assimilating observed aerosol optical depth in a global aerosol model. Atmos. Chem. Phys., 12, 45854606, doi:10.5194/acp-12-4585-2012.

Konare, A., A. S. Zakey, F. Solmon, F. Giorgi, S. Rauscher, S. Ibrah, and X. Bi, 2008: A regional climate modeling study of the effect of desert dust on the West African monsoon. J. Geophys. Res., 113, D12206, doi:10.1029/2007JD009322.

Lau, K. M., and K. M. Kim, 2006: Observational relationships between aerosol and Asian monsoon rainfall, and circulation. Geophys. Res. Lett., 33, L21810, doi:10.1029/ 2006 GL027546. 
— M. K. Kim, and K. M. Kim, 2006: Asian summer monsoon anomalies induced by aerosol direct forcing: The role of the Tibetan Plateau. Climate Dyn., 26, 855-864, doi:10.1007/ s00382-006-0114-z.

—, K. M. Kim, Y. C. Sud, and G. K. Walker, 2009: A GCM study of the response of the atmospheric water cycle of West Africa and the Atlantic to Saharan dust radiative forcing. Ann. Geophys., 27, 4023-4037, doi:10.5194/angeo-27-4023-2009.

—, M. K. Kim, K. M. Kim, and W. S. Lee, 2010: Enhanced surface warming and accelerated snow melt in the Himalayas and Tibetan Plateau induced by absorbing aerosols. Environ. Res. Lett., 5, 025204, doi:10.1088/1748-9326/5/2/025204.

Menon, S., J. Hansen, L. Nazarenko, and Y. Luo, 2002: Climate effects of black carbon aerosols in China and India. Science, 297, 2250-2253, doi:10.1126/science.1075159.

Miller, R. L., and I. Tegen, 1998: Climate response to soil dust aerosols. J. Climate, 11, 3247-3267, doi:10.1175/1520-0442(1998)011<3247: CRTSDA $>2.0 . \mathrm{CO} ; 2$

— J. Perlwitz, and I. Tegen, 2004a: Feedback upon dust emission by dust radiative forcing through the planetary boundary layer. J. Geophys. Res., 109, D24209, doi:10.1029/ 2004JD004912.

— I. Tegen, and J. Perlwitz, 2004b: Surface radiative forcing by soil dust aerosols and the hydrologic cycle. J. Geophys. Res., 109, D04203, doi:10.1029/2003JD004085.

Milton, S. F., G. Greed, M. E. Brooks, J. Haywood, B. Johnson, R. P. Allan, A. Slingo, and W. M. F. Grey, 2008: Modeled and observed atmospheric radiation balance during the West African dry season: Role of mineral dust, biomass burning aerosol, and surface albedo. J. Geophys. Res., 113, D00C02, doi:10.1029/ 2007JD009741.

Nicholson, S. E, 2009. A revised picture of the structure of the "monsoon" and land ITCZ over West Africa. Climate Dyn., 32, 1155-1171, doi:10.1007/s00382-008-0514-3.

Parker, D. J., C. D. Thorncroft, R. R. Burton, and A. DiongueNiang, 2005: Analysis of the African easterly jet, using aircraft observations from the JET2000 experiment. Quart. J. Roy. Meteor. Soc., 131, 1461-1482, doi:10.1256/qj.03.189.

Pérez, C., S. Nickovic, G. Pejanovic, J. M. Baldasano, and E. Özsoy, 2006: Interactive dust-radiation modeling: A step to improve weather forecasts. J. Geophys. Res., 111, D16206, doi:10.1029/ 2005JD006717.

Perlwitz, J., and R. L. Miller, 2010: Cloud cover increase with increasing aerosol absorptivity: A counterexample to the conventional semidirect aerosol effect. J. Geophys. Res., 115, D08203, doi:10.1029/2009JD012637.

_ I. Tegen, and R. L. Miller, 2001: Interactive soil dust aerosol model in the GISS GCM: 1 . Sensitivity of the soil dust cycle to radiative properties of soil dust aerosols. J. Geophys. Res., 106, 18167-18192, doi:10.1029/2000JD900668.

Pye, K., 1987: Aeolian Dust and Dust Deposits. Academic Press, $334 \mathrm{pp}$.

Rodwell, M. J., and T. Jung, 2008: Understanding the local and global impacts of model physics changes: An aerosol example. Quart. J. Roy. Meteor. Soc., 134, 1479-1497, doi:10.1002/qj.298.

Ryder, C. L., and Coauthors, 2013: Optical properties of Saharan dust aerosol and contribution from the coarse mode as measured during the Fennec 2011 aircraft campaign. Atmos. Chem. Phys., 13, 303-325, doi:10.5194/acp-13-303-2013.

Shaffrey, L. C., and Coauthors, 2009: U.K. HiGEM: The new U.K. High-Resolution Global Environment Model-Model description and basic evaluation. J. Climate, 22, 1861-1896, doi:10.1175/2008JCLI2508.1.
Sokolik, I. N., A. Androvna, and T. C. Johnson, 1993: Complex refractive index of atmospheric dust aerosols. Atmos. Environ., 27, 2495-2502, doi:10.1016/0960-1686(93)90021-P.

— O. B. Toon, and R. W. Bergstrom, 1998: Modelling the radiative characteristics of airborne mineral aerosols at infrared wavelengths. J. Geophys. Res., 103, 8813-8826, doi:10.1029/ 98JD00049.

Solmon, F., M. Mallet, N. Elguindi, F. Giorgi, A. Zakey, and A. Konaré, 2008: Dust aerosol impact on regional precipitation over western Africa, mechanisms and sensitivity to absorption properties. Geophys. Res. Lett., 35, L24705, doi:10.1029/ 2008GL035900.

—- N. Elguindi, and M. Mallet, 2012: Radiative and climatic effects of dust over West Africa, as simulated by a regiona climate model. Climate Res., 52, 97-113, doi:10.3354/ cr01039.

Tegen, I., and A. Lacis, 1996: Modeling of particle size distribution and its influence on the radiative properties of mineral dust aerosol. J. Geophys. Res., 101, 19237-19244, doi:10.1029/ 95JD03610.

Todd, M. C., and Coauthors, 2008: Quantifying uncertainty in estimates of mineral dust flux: An intercomparison of model performance over the Bodélé Depression, northern Chad. J. Geophys. Res., 113, D24107, doi:10.1029/2008JD010476.

Tompkins, A. M., C. Cardinali, J.-J. Morcrette, and M. Rodwell, 2005: Influence of aerosol climatology on forecasts of the African easterly jet. Geophys. Res. Lett., 32, L10801, doi:10.1029/ 2004GL022189.

Weinzierl, B., and Coauthors, 2011: Microphysical and optical properties of dust and tropical biomass burning aerosol layers in the Cape Verde region-An overview of the airborne in situ and lidar measurements during SAMUM-2. Tellus, 63B, 589618, doi:10.1111/j.1600-0889.2011.00566.x.

Wilcox, E. M., K. M. Lau, and K.-M. Kim, 2010: A northward shift of the North Atlantic Ocean intertropical convergence zone in response to summertime Saharan dust outbreaks. Geophys. Res. Lett., 37, L04804, doi:10.1029/2009GL041774.

Wilson, M. F., and A. Henderson-Sellers, 1985: A global archive of land cover and soils data for use in general circulation climate models. Int. J. Climatol., 5, 119-143, doi:10.1002/ joc.3370050202.

Woodage, M. J., A. Slingo, S. Woodward, and R. E. Comer, 2010: U.K. HiGEM: Simulations of desert dust and biomass burning aerosols with a high-resolution atmospheric GCM. J. Climate, 23, 1636-1659, doi:10.1175/2009JCLI2994.1.

Woodward, S., 2001: Modelling the atmospheric life cycle and radiative impact of mineral dust in the Hadley Centre climate model. J. Geophys. Res., 106, 18155-18166, doi:10.1029/ 2000JD900795.

Xie, P., and P. A. Arkin, 1997: Global precipitation: A 17-year monthly analysis based on gauge observations, satellite estimates, and numerical model outputs. Bull. Amer. Meteor. Soc., 78, 2539-2558, doi:10.1175/1520-0477(1997)078<2539:GPAYMA >2.0.CO;2.

Yoshioka, M., N. M. Mahowald, A. J. Conley, W. D. Collins, D. W. Fillmore, C. S. Zender, and D. B. Coleman, 2007: Impact of desert dust radiative forcing on Sahel precipitation: Relative importance of dust compared to sea surface temperature variations, vegetation changes, and greenhouse gas warming. J. Climate, 20, 1445-1467, doi:10.1175/JCLI4056.1.

Yue, X., H. Liao, H. J. Wang, S. L. Li, and J. P. Tang, 2011: Role of sea surface temperature responses in simulation of the climatic effect of mineral dust aerosol. Atmos. Chem. Phys., 11, 60496062, doi:10.5194/acp-11-6049-2011. 